\title{
Deletion of the Mitochondrial Complex-IV Check for updates Cofactor Heme A:Farnesyltransferase Causes Focal Segmental Glomerulosclerosis and Interferon Response
}

\author{
Jea-Hyun Baek, ${ }^{*}$ Ivan G. Gomez, ${ }^{* \dagger}$ Yukihiro Wada, ${ }^{\ddagger}$ Allie Roach, ${ }^{* \dagger}$ Don Mahad, ${ }^{\S}$ and Jeremy S. Duffield ${ }^{* \dagger}$
}

\begin{abstract}
From Research and Development, * Biogen Inc., Cambridge, Massachusetts; the Division of Nephrology, ${ }^{\dagger}$ Departments of Medicine and Pathology, University of Washington, Seattle, Washington; the Division of Nephrology, ${ }^{\ddagger}$ Department of Medicine, Showa University School of Medicine, Tokyo, Japan; the Centre for Clinical Brain Sciences, ${ }^{\S}$ Anne Rowling Regenerative Neurology Clinic and Centre for Neuroregeneration, University of Edinburgh, Edinburgh, United Kingdom; and the Division of Nephrology, ${ }^{\circledR}$ Department of Medicine, Massachusetts General Hospital, Boston, Massachusetts
\end{abstract}

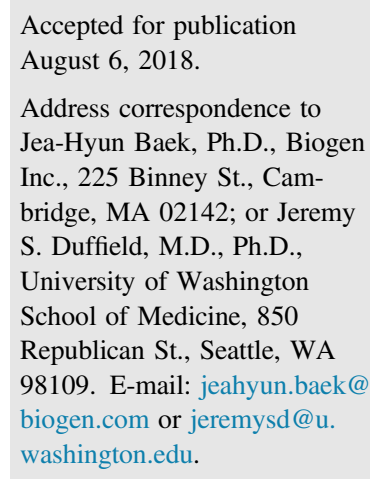

\begin{abstract}
Mutations in mitochondrial DNA as well as nuclear-encoded mitochondrial proteins have been reported to cause tubulointerstitial kidney diseases and focal segmental glomerulosclerosis (FSGS). Recently, genes and pathways affecting mitochondrial turnover and permeability have been implicated in adultonset FSGS. Furthermore, dysfunctioning mitochondria may be capable of engaging intracellular innate immune-sensing pathways. To determine the impact of mitochondrial dysfunction in FSGS and secondary innate immune responses, we generated Cre/lox $P$ transgenic mice to generate a loss-of-function deletion mutation of the complex IV assembly cofactor heme A:farnesyltransferase (COX10) restricted to cells of the developing nephrons. These mice develop severe, early-onset FSGS with innate immune activation and die prematurely with kidney failure. Mutant kidneys showed loss of glomerular and tubular epithelial function, epithelial apoptosis, and, in addition, a marked interferon response. In vitro modeling of Cox10 deletion in primary kidney epithelium compromises oxygen consumption, ATP generation, and induces oxidative stress. In addition, loss of Cox10 triggers a selective interferon response, which may be caused by the leak of mitochondrial DNA into the cytosol activating the intracellular DNA sensor, stimulator of interferon genes. This new animal model provides a mechanism to study mitochondrial dysfunction in vivo and demonstrates a direct link between mitochondrial dysfunction and intracellular innate immune response. (Am J Pathol 2018, 188: 2745-2762; https:// doi.org/10.1016/j.ajpath.2018.08.018)
\end{abstract}

Focal segmental glomerulosclerosis (FSGS) is a pathologic diagnosis made in the setting of proteinuric kidney disease. It is characterized by initial disease of podocytes of the glomerular tuft, frequently associated with tubulointerstitial disease, which is most often proportionate to the severity of glomerular disease. Several mutations in causal genes have been identified in familial FSGS, including those coding for structural proteins of the slit diaphragm of the podocyte. ${ }^{1}$ Nevertheless, most patients do not have a recognized mutation that causes disease, and, in some circumstances, FSGS may be an adaptive manifestation to hyperfiltration. During the past 15 years, case reports have suggested mutations of mitochondrial DNA (mtDNA) may cause several familial and sporadic cases of FSGS, as well as tubular diseases, such as Fanconi syndrome and tubulointerstitial nephritis. Rarely, nuclear genes coding for mitochondrial proteins have been implicated, but these reports have often described kidney disease in the setting of systemic disorders, pointing to widespread mitochondrial disease. ${ }^{2-4}$ In addition, xenobiotics to treat viral infections and malignancies have been proposed to directly damage mitochondria, causing tubulointerstitial disease. Recently, polymorphisms in an innate immune protein, apolipoprotein L1 (APOL1), have

Supported by NIH grants DK093493 and DK094768 (J.S.D.) and Biogen Inc.

Disclosures: I.G.G., A.R., and J.S.D. hold stock in Biogen, Inc. and J.S.D. holds a patent for treatment of Alport syndrome with a therapy that enhances mitochondrial biogenesis. 
been found to be associated with high risk of developing FSGS in patients of African ancestry, and potentially playing a causative role in a much larger fraction of patients who present with proteinuric progressive kidney disease. ${ }^{5}$ Biochemical and cell-based studies suggest intracellular, not circulating, APOL1 may directly disrupt the mitochondrial transmembrane potential in podocytes, to cause podocyte dysfunction. ${ }^{6,7}$ In addition, disruption or dysfunction of mitochondrial turnover by loss of mitochondrial quality control (mitophagy) has been demonstrated to directly cause FSGS in patients and animal models. ${ }^{8,9}$ Such studies strongly implicate mitochondrial dysfunction in the pathogenesis of proteinuric kidney diseases. ${ }^{10,11}$ Moreover, single-nucleotide polymorphisms in the regulatory sequences of the energy sensor and mitochondrial regulator, AMP-activated protein kinase (PPKAG2), and other mitochondrial metabolism genes, such as carbamoyl phosphate synthase I (CPS1) and glucokinase regulator $(G C K R)$, have been implicated in hypertensive and diabetic kidney diseases with proteinuria from highly powered genome-wide association studies. ${ }^{12}$

Several mechanisms by which mitochondrial dysfunction can result in FSGS have been reported. ${ }^{13-18}$ Mitochondrial disease causes increased intracellular reactive oxygen species generation. In certain circumstances, oxidative damage to local organelles, including endoplasmic reticulum and DNA, can occur, although the absolute importance of mitochondrial reactive oxygen species to disease remains unclear. Impaired clearance of defective mitochondrial components, known as mitophagy, also leads to enlarged mitochondria generating reduced ATP and enhanced reactive oxygen species. A reduction in oxidative phosphorylation can compromise cellular function, particularly in cells that rely heavily on mitochondria for ATP generation, including podocytes and epithelium of the kidney.

Mitochondria have many functions in addition to metabolism and oxidative phosphorylation. They are critical in detoxification, iron-sulfur cluster biogenesis, intracellular calcium regulation, and central regulation of cell death/ survival pathways, including caspase-mediated apoptosis. In addition, mitochondria have been shown to be important sensors and structural regulators of intracellular innate immune responses to pathogens. ${ }^{19-24}$ Some of the intracellular sensors used to detect intracellular pathogens include the retinoic acid-inducible gene-I-like proteins, stimulator of interferon genes (STING), mitochondrial antiviral signaling protein, cyclic GMP-AMP synthase, and interferon$\gamma$-inducible protein 16 , which sense viral RNA and DNA. ${ }^{19,20,25-29}$ It has been proposed that the leakage of mtDNA from dysfunctioning or disrupted mitochondria could additionally directly activate STING, the DNA sensor, providing a direct potential link between mitochondrial disease and inflammatory response. ${ }^{20,30}$ However, abundant extracellular mtDNA can be found in tissue injury but does not activate toll-like receptors that sense extracellular foreign DNA, except in rare circumstances in which the DNA is reported to be highly oxidized..$^{31}$ Therefore, the role of mtDNA leakage in innate immune responses and its contribution to pathogenesis in the setting of noninfectious kidney disease are unexplored.

In the following studies, we validated the hypothesis that mutation of a single gene that contributes to complex IV (COX-IV) stability in the electron transport chain is sufficient to cause the pathologic manifestations of FSGS and determined in a controlled manner whether mutation-driven mitochondrial dysfunction directly activates sensors of viral DNA sufficient to trigger an interferon response. To this end, nephron-specific complex IV assembly cofactor heme A:farnesyltransferase (Cox10) conditional knockout mice $\left(\operatorname{Cox} 10^{f / f}\right)^{32}$ expressing Cre under the control of the Six2

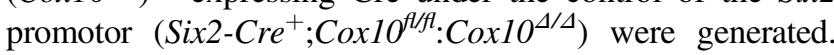
The nephron is the structural and functional unit involved in all key processes, including filtration, reabsorption, secretion, and excretion. In bigenic, homozygous, floxed mice, Cox10 was disrupted in Six2-expressing nephron progenitors and their progeny, which form the mesenchyme-derived kidney epithelium, including podocytes, parietal epithelial cells, proximal tubules, loops of Henle, and distal tubules. ${ }^{33,34}$ Cox10 encodes a heme $\mathrm{A} /$ farnesyl transferase, ${ }^{35}$ which is required for the correct assembly of cytochrome $c$ oxidase (COX-IV; alias the complex IV of the electron transport chain), a critical complex in mitochondrial respiratory ATP production. ${ }^{36}$ Genetic deletion of Cox10 causes COX-IV deficiency, in turn leading to mitochondrial dysfunction. ${ }^{32,37,38}$

\section{Materials and Methods}

Mice

Mice harboring loxP-flanked Cox 10 alleles $^{32}$ were crossed to a mouse strain expressing Cre under the Six 2 promotor to generate nephron-specific Cox10 conditional knockout mice

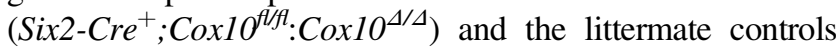
carrying either unexcised floxed or Cox10 wild-type (WT) gene on both alleles $\left(\mathrm{Cox} \mathrm{O}^{+/+}\right)$. To test prenatal lethality of

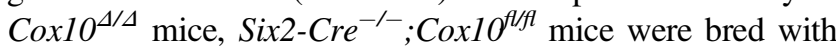
$\mathrm{Six} 2-\mathrm{Cre}^{+/-} ; \mathrm{Cox}_{10^{f /+}}$. Studies were performed under approved Institutional Animal Care and Use Committee protocols (0489-2013 and 755) at Biogen Inc. (Cambridge, MA) and the University of Washington (Seattle, WA; protocol 4244). ${ }^{39}$

\section{Renal Histopathology}

Kidneys were resected after systemic perfusion with ice-cold phosphate-buffered saline (PBS). Paraffinembedded sections of kidney fixed with neutral-buffered formalin were used for periodic acid-Schiff, methenamine silver, and picrosirius red staining, as described previously. ${ }^{9}$

\section{Histologic Analysis}

Glomerular pathology was evaluated by an observer-blinded pathologist (Y.W.) assessing all glomeruli of whole cortex 
of a sagittal section of the whole kidney from each mouse ( $\times 40$ magnification) in periodic acid-Schiff- or methenamine silver-stained kidney sections, as described in several previous publications. ${ }^{9,40,41}$ Between 42 and 71 glomeruli were scored sequentially per animal. Each glomerular section was quantified for the percentage of sclerotic glomeruli (capillary loop obliteration and replacement with sclerotic matrix). Up to $25 \%$ of tuft involved scored 1, up to $50 \%$ of tuft scored 2, up to $75 \%$ of tuft scored 3, and up to $100 \%$ of tuft scored 4. Visceral epithelial cell hyperplasia with collapsing-type lesions (pseudocrescents) was defined as more than two layers of epithelial cells with the parietal basement membrane. Tubular pathology was evaluated by assessing 10 randomly selected microscopic fields $(\times 10$ magnification) of the outer medulla per animal in periodic acid-Schiff-stained kidney sections and determining the numbers of dilated, atrophic tubules and tubules with casts.

\section{Electron Microscopy}

The protocol for tissue preparation and staining for transmission electron microscopy has been described previously. ${ }^{42}$ Grids were scanned using a JEM-1380 electron microscope (Jeol, Peabody, MA).

\section{Renal Function}

Serum and urinary creatinine were measured using Creatinine Liquid Reagents Assay (Diazyme, San Diego, CA) or a urinary creatinine detection kit (Thermo Fisher Scientific, Carlsbad, CA). Blood urea nitrogen levels were detected by blood urea nitrogen (Pointe Scientific, Canton, MI). Urinary albumin concentration was measured using an Albuwell M kit (Exocell, Philadelphia, PA).

\section{Immunostaining of Kidney Sections}

Kidneys were fixed with periodate-lysine-paraformaldehyde fixative. After immersion in PBS, including 18\% sucrose at $4{ }^{\circ} \mathrm{C}$ overnight, they were embedded and frozen in optimal cutting temperature compound (Sakura Finetek, Torrance, CA). Cryostat-cut mouse kidney sections (5 $\mu \mathrm{m}$ thick) were stained for the following: fibrosis, using Cy3-conjugated anti- $\alpha$-smooth muscle actin antibody $(\mathrm{Ab} ; ; 1: 200$; clone 1A4; Sigma-Aldrich, St. Louis, MO); tubular injury, using polyclonal rabbit anti-human kidney injury molecule-1 $\mathrm{Ab}$ (1:200; catalog ab47635; Abcam, Cambridge, MA); apoptosis, using rabbit anti-human cleaved caspase-3 $\mathrm{Ab}$ (1:50; clone 5A1E; Cell Signaling Technology, Danvers, MA); proximal tubules, using fluorescein isothiocyanateconjugated lotus tetragonolobus lectin (LTL; 1:200; catalog FL-1321; Vector Laboratories, Burlingame, CA); and macrophages, using rat anti-mouse F4/80 Ab (1:400; clone BM-8; Thermo Fisher Scientific). This was followed by Cy3-conjugated donkey anti-rabbit IgG Ab, Alexa Fluor 488 donkey anti-rabbit IgG antibody, and Cy3-conjugated donkey anti-rat IgG Ab (1:400; Jackson ImmunoResearch, West Grove, PA). All sections were mounted with mounting medium containing 4',6-diamidino-2-phenylindole (DAPI; catalog P36931; Thermo Fisher Scientific). Images were taken using an LSM 710 laser-scanning confocal microscope (Zeiss, Thornwood, NY). The magnitude of staining was analyzed in 10 microscopic fields per animal using Adobe Photoshop CC 2017 (Adobe Systems, San Jose, CA).

\section{SDS-PAGE and Western Blot Analysis}

SDS-PAGE and Western blot analysis were performed as described previously. ${ }^{9,43}$ To detect total and phosphorylated STING, protein electrophoresis was performed using 7.5\% SuperSep Phos-tag gel (Wako, Richmond, VA). Primary antibodies used were as follows: polyclonal rabbit anticytochrome c oxidase subunit I (COX1; 1:1000; catalog PA5-26688; Thermo Fisher Scientific), rabbit anti-COX10 (1:1000; catalog MBS2526567; MyBiosource Inc., San Diego, CA), monoclonal rabbit anti-interferon regulatory factor 1 (IRF1; 1:1000; clone D5E4; Cell Signaling Technology), rabbit anti-2'-5'-oligoadenylate synthase 1 (OAS1; 1:1000; clone D1W3A; Cell Signaling Technology), rabbit anti-STAT3 (1:1000; clone 79D7; Cell Signaling Technology), rabbit anti-STING (1:1000; clone D1V5L; Cell Signaling Technology), rabbit anti-TRAF family member-associated NFkappaB activator (TANK)binding kinase-1 [TBK1; 1:2000; clone EPR2867(2)-19; Abcam], rabbit anti-phosphorylated TBK1 (1:250; clone D52C2; Cell Signaling Technology), and mouse antiglyceraldehyde-3-phosphate dehydrogenase Ab (1:2000; clone GT239; GeneTex, Irvine, CA).

\section{Gene Ontology and Pathway Enrichment Analysis}

Total RNA was extracted from kidney biopsy specimens

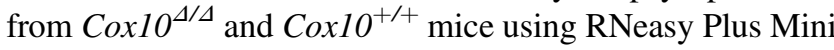
Kit (Qiagen, Hilden, Germany). Purity was determined by measuring the 260/280 and 260/239 ratio. Gene expression profiling was performed using next-generation sequencing on the Illumina HiSeq 2500 platform producing 50-bp paired-end reads. Total reads were mapped using the aligner STAR. ${ }^{44}$ Genes were quantified with RSEM, ${ }^{45}$ and differential expression was determined by DESeq2 using Array Studio 10 (OmicSoft, Cary, NC). ${ }^{46}$ Significantly differentially expressed genes were selected according to the following criteria: false discovery rate-corrected $P<0.001$ and fold change $>1.4$-fold. Analysis was subjected to the enrichment test for gene ontology and pathway analysis through the use of Ingenuity Pathway Analysis version 01$10^{47}$ (Qiagen) or DAVID version 6.8 (http://david.ncifcrf. gov). ${ }^{48,49}$ Differentially expressed genes were subjected to functional protein association analysis using STRING database version 10.5 (http://www.string-db.org, last accessed March 16, 2018, registration required). Differentially expressed genes were interferon-stimulated 
genes (ISGs) and were identified using the online database INTERFEROME version 2.01 ( $h t t p: / / w w w$.interferome.org/ interferome/home.jspx, last accessed March 19, 2018). Because the RNA was directly sequenced, PCR confirmation of transcriptional changes was not considered necessary. All RNA sequencing data and expression values are available at the Gene Expression Omnibus repository at the National Center for Biotechnology Information (http://www.ncbi.nlm.nih.gov/geo; accession number GSE117681).

\section{Isolation and Culture of Primary Kidney Tubular} Epithelial Cells

Kidneys from WT mice at 2 to 3 months of age were harvested, decapsulated, diced, and then incubated at $37^{\circ} \mathrm{C}$ for 60 minutes with liberase thermolysin low $(0.2 \mathrm{mg} / \mathrm{mL}$; Roche, Indianapolis, IN) in the presence of DNase I (100 U/ $\mathrm{mL}$ ) in serum-free Dulbecco's modified Eagle's medium/ F12 medium. After filtration $(40 \mu \mathrm{m})$, proximal tubular epithelial cells (PTECs) were enriched using Dynabeads biotin-binder (Thermo Fisher Scientific) in combination with biotinylated LTL (Vector Laboratories). Unbound cells (including uncaptured PTECs) were further purified for TECs by immunomagnetic bead purification using magnetic-activated cell sorting anti-mouse CD326 [epithelial cell adhesion molecule $\left(\right.$ EpCAM) $\left.{ }^{+}\right]$microbeads (Miltenyi Biotec, Auburn, CA). PTECs $\left(\mathrm{LTL}^{+}\right)$and TECs $\left(\mathrm{EpCAM}^{+}\right)$were cultured in renal epithelial cell growth basal medium renal growth basal medium (Lonza, Walkersville, MD) supplemented with renal epithelial cell growth medium SingleQuot Kit Supplements \& Growth Factors (Lonza).

\section{Cox10 Silencing}

PTECs and TECs were transfected with $100 \mathrm{nmol} / \mathrm{L}$ of siRNA for Cox10 (Silencer Select siRNA; catalog number 4390771; identifier s88774) and control siRNA (Silencer Select Negative Control\#2; catalog number 4390846) preincubated with Lipofectamine RNAiMAX in OptiMEM (all from Thermo Fisher Scientific) for 5 minutes, according to the manufacturer's protocol. At days 2 and 5 of transfection, transfected cells were analyzed for Cox10 knockdown and transcriptional changes.

\section{Quantitative PCR}

Total RNA was extracted using the RNeasy Plus Mini Kit (Qiagen). Purity was determined by measuring the 260/280 and 260/230 ratios. cDNA was synthesized using random primers and reverse transcriptase (iScript cDNA Synthesis Kit; Bio-Rad, Hercules, CA). TaqMan real-time PCR was performed using the QuantStudio 12K Flex Real-Time PCR System in a duplex reaction with the gene of interest (FAM probe) and Gapdh as the housekeeping gene (VIC probe).
Table 1 TaqMan Primers Used in the Study

\begin{tabular}{ll}
\hline Gene & Assay identifier \\
\hline Casp3 & Mm01195085_m1 \\
Casp6 & Mm01321726_g1 \\
Casp7 & Mm01259818_m1 \\
Casp8 & Mm01255716_m1 \\
Cox10 exon 3-4 & Mm01332417_m1 \\
Cox10 exon 6-7 & Mm00617695_m1 \\
Cxcl10 & Mm00445234_m1 \\
Ddx58 & Mm01216853_m1 \\
Gapdh* & Mm99999915_g1 \\
Ifih1 & Mm00459183_m1 \\
Ifit1 & Mm00515153_m1 \\
Ifit3 & Mm01704846_s1 \\
Ifna2 & Mm00833961_s1 \\
Ifna4 & Mm00833969_s1 \\
Ifnb1 & Mm00439552_s1 \\
Il1b & Mm00434228_m1 \\
Irf7 & Mm00516793_g1 \\
Isg15 & Mm01705338_s1 \\
Nlrx1 & Mm00617978_m1 \\
Sdhd & Mm00546511_m1 \\
Sod1 & Mm01344233_g1 \\
Sod2 & Mm01313000_m1 \\
Stat1 & Mm00439531_m1 \\
Tnf & Mm00443258_m1 \\
Usp18 & Mm01188805_m1 \\
\hline
\end{tabular}

*Housekeeping gene.

The mRNA expression was calculated using the $\Delta \Delta \mathrm{C}_{\mathrm{T}}$ method and expressed as a fold difference relative to the untreated group. All TaqMan probes used in this study are listed in Table 1.

\section{Measurement of Mitochondrial Function}

The oxygen consumption rate was measured using a Seahorse XFe96 extracellular flux analyzer (Agilent Technologies, Santa Clara, CA), according to the manufacturer's instructions. Total cellular ATP production by cultured TECs was measured using the CellTiter-Glo Luminescent Cell Viability Assay kit (Promega, Madison, WI), according to the manufacturer's instructions. Cell viability and mitochondrial membrane potential were measured using the HCS Mitochondrial Health Kit (catalog number H10295; Thermo Fisher Scientific), according to the manufacturer's instructions. Mitochondrial membrane potential was normalized by mitochondrial mass by coincubating TECs with $75 \mathrm{nmol} / \mathrm{L}$ MitoTracker Green FM (catalog number M7514; Thermo Fisher Scientific) and determining the ratio of mitochondrial membrane potential (MMP)/MitoTracker Green FM fluorescence intensity.

\section{Immunofluorescence Microscopy for mtDNA}

Before staining, cultured cells were washed in PBS, fixed with $4 \%$ paraformaldehyde for 20 minutes at room temperature, permeabilized with $0.1 \%$ Triton X-100 in PBS for 
5 minutes, and blocked with $10 \%$ fetal bovine serum in PBS for 30 minutes. Then, cells were costained with polyclonal rabbit anti-human superoxide dismutase $2 \mathrm{Ab}$ (1:50; catalog number ab13353; Abcam) for mitochondria and mouse antiDNA Ab (1:50; clone AC-30-19; EMD Millipore, Burlington, MA), followed by Alexa Fluor 488-conjugated goat anti-rabbit $\operatorname{IgG~Ab}$ and Alexa Fluor 594 goat antimouse IgG antibody (1:750; all from Thermo Fisher Scientific). Cells were washed $3 \times$ in PBS containing $5 \mu \mathrm{g} / \mathrm{mL}$ Hoechst 33342 (Thermo Fisher Scientific) for 5 minutes and imaged on an Opera Phenix High-Content Screening System with a $63 \times$ water-immersed objective (PerkinElmer, Waltham, MA).

\section{Detection of Cytosolic mtDNA}

Cytosolic and whole-cell DNAs were extracted as described previously. ${ }^{20,50}$ Briefly, cultured TECs $\left(8 \times 10^{6}\right)$ were divided into two equal aliquots. Whole-cell DNA was extracted from one aliquot using DNeasy Blood \& Tissue Kit (Qiagen) after a 10-minute incubation with proteinase $\mathrm{K}$ (500 $\mu \mathrm{L} ; 100 \mathrm{mmol} / \mathrm{L}$ tris-HCl, $\mathrm{pH} 8.5,5 \mathrm{mmol} / \mathrm{L}$ EDTA, $\mathrm{pH} 8.0$, $0.2 \% \mathrm{SDS}, 200 \mathrm{mmol} / \mathrm{L} \mathrm{NaCl}$, and $100 \mu \mathrm{g} / \mathrm{mL}$ proteinase $\mathrm{K}$ ). Cytosolic mtDNA was purified from the second aliquot using QIAquick Nucleotide Removal Columns (Qiagen) after digestion with digitonin $[500 \mu \mathrm{L} ; 150 \mathrm{mmol} / \mathrm{L} \mathrm{NaCl}, 50$ $\mathrm{mmol} / \mathrm{L}$ HEPES, $\mathrm{pH} 7.4$, and $20 \mu \mathrm{g} / \mathrm{mL}$ digitonin (EMD Millipore)] and subsequent centrifugations: $3 \times$ at $980 \times g$ for 5 minutes and $1 \times$ at $17,000 \times g$ for 25 minutes. Quantitative PCR was performed on both whole-cell and cytosolic fractions using nuclear DNA primers (Tert) and mtDNA primers (Dloop1 to Dloop3), and the $\mathrm{C}_{\mathrm{T}}$ values for mtDNA-encoded genes obtained from whole-cell extracts served as normalization controls for the mtDNA values obtained from the cytosolic fractions. Primers used were as follows: Tert, $5^{\prime}-$ CTAGCTCATGTGTCAAGACCCTCTT-3' (forward) and 5'-GCCAGCACGTTTCTCTCGTT-3' (reverse); mtDNA Dloop 1, 5'-AATCTACCATCCTCCGTGAAACC-3' (forward) and $5^{\prime}$-TCAGTTTAGCTACCCCCAAGTTTAA-3' (reverse); mtDNA Dloop2, 5'-CCCTTCCCCATTTGGTCT-3' (forward) and 5'-TGGTTTCACGGAGGATGG-3' (reverse); and mtDNA Dloop3, 5'-TCCTCCGTGAAACCAACAA-3' (forward) and 5'-AGCGAGAAGAGGGGCATT-3' (reverse).

\section{mtDNA Preparation and Transfection into TECs}

The 2.6- and 3.6-kb fragments of mtDNA were amplified from whole-cell DNA extracted from untreated TECs in the presence or absence of 8-oxo-dGTP (TriLink Biotechnologies, San Diego, CA), as described previously. ${ }^{51}$ Thereby, we used following primers: $2.6 \mathrm{~kb}, 5^{\prime}$-AATCTACCATCCTCCGTGAAACC-3' (forward) and 5'-ATACCGCGGCCGTTAAA$3^{\prime}$ (reverse); and $3.6 \mathrm{~kb}, 5^{\prime}$-AACGGATCCACAGCCGTA- $3^{\prime}$ (forward) and $5^{\prime}$-TGTTGGGTTGTTTGATCCTG- ${ }^{\prime}$ (reverse). Without further purification, amplified mtDNA fragments $(4 \mu \mathrm{g} / \mathrm{mL})$ were transfected into TECs using
Lipofectamine RNAiMAX Transfection Reagent (Thermo Fisher Scientific).

\section{Statistical Analysis}

Data represent the means \pm SEM. Differences between groups were assessed by the $U$-test. $P<0.05$ was considered statistically significant.

\section{Results}

\section{Cox $10^{4 / \Delta}$ Mice Develop a Severe Form of FSGS}

To disrupt the CoxlO gene in the nephron only, Cox $10^{A / f t}$ mice were crossed with a well-validated bacterial artificial chromosome transgenic mouse that expresses Cre under the control of the Six2 promoter to generate nephron-specific Cox10 knockout mice $\left(\operatorname{Cox} 10^{4 / 4}\right)$. Six2 encodes a transcription factor exclusively expressed in cap mesenchyme during nephrogenesis. ${ }^{33} \mathrm{Six}^{+}$cap mesenchyme cells are progenitors that produce all of the epithelial cells of the nephron, except the collecting duct. Thereby, exon 6 of Cox10 encoding part of the enzymatic active site of COX10 was deleted in nephron progenitors and their progeny (podocytes, parietal epithelial cells, proximal tubules, loops of Henle, and distal tubules), ${ }^{9,33}$ resulting in the out-offrame truncation and loss of COX10 protein in the glomerular and tubular epithelium, except the collecting ducts. ${ }^{32}$ Cohorts of mice were bred, and kidney pathology in $\operatorname{Cox} 10^{4 / \Delta}$ and WT littermates $\left(\operatorname{Cox} 10^{+/+}\right)$was evaluated at 3 months of age. Successful mutation of the Coxl0 gene was confirmed by quantification of COX10 protein. COX10 protein was markedly decreased in the whole kidney of Cox $10^{4 / \Delta}$ compared with Cox $10^{+/+}$kidneys. Correspondingly, $\operatorname{Cox} 10^{\Delta / \Delta}$ kidneys showed decreased levels of the main subunit of cytochrome $c$ oxidase, COX-IV (named COX1), indicating that $\operatorname{Cox} 10^{4 / \Delta}$ kidneys harbor less fully assembled COX-IV because of conditional gene targeting (Supplemental Figure S1A). Cox $10^{\Delta / \Delta}$ kidneys have typical features of FSGS (Figure 1A). These features include a segmental pattern of scarring, showing obliterated capillary loops, hyaline deposition, and adhesion of tuft to the Bowman capsule; glomeruli with perihilar predominance of sclerosis or hyalinosis; segmental sclerosis at the tubular pole of the glomerulus; and glomeruli with tuft collapse associated with glomerular epithelial cell proliferation (Figure 1, A and B). These are similar to the features of FSGS in the nephron-specific autophagy-deficient mouse model reported previously.

$\operatorname{Cox} 10^{4 / 4}$ mice showed an advanced stage of glomerulosclerosis at 3 months of age, where almost all glomeruli had segmental scars. Segmental sclerosis was present in $18.0 \% \pm 4.6 \%$, and global glomerulosclerosis was present in $48.3 \% \pm 8.7 \%$. In addition, glomerular epithelial proliferation (pseudocrescents), similar to the collapsing form of FSGS, was found in $45.3 \% \pm 8.5 \%$ (Figure 1C). Electron 


\section{A PAS staining}
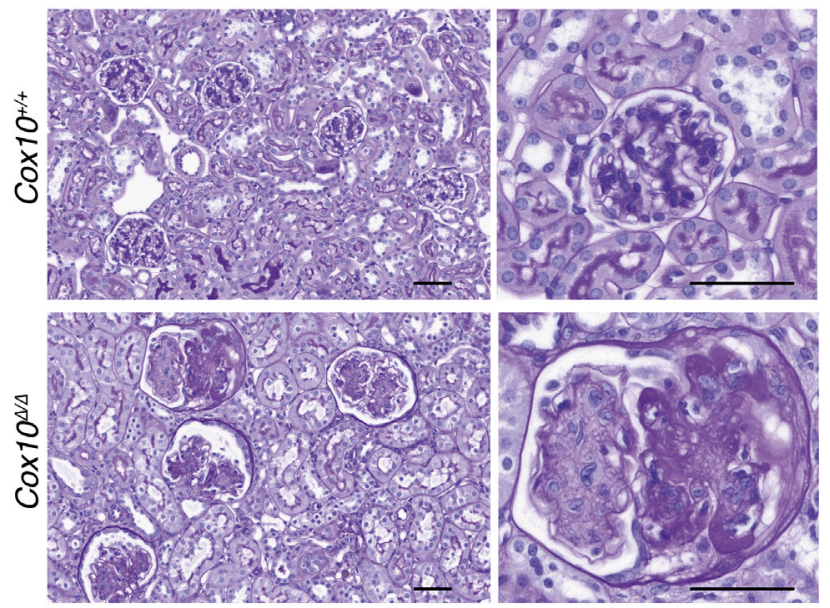

C Pathology

Sclerotic glomeruli

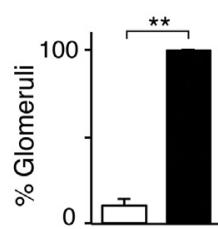

Glomerulosclerosis severity score

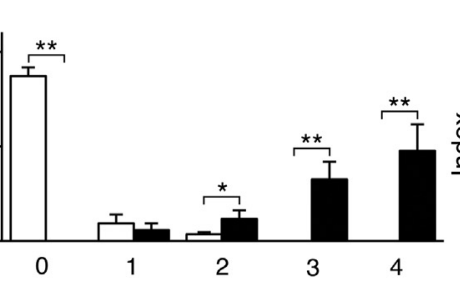
Glomerulo- sclerosis index
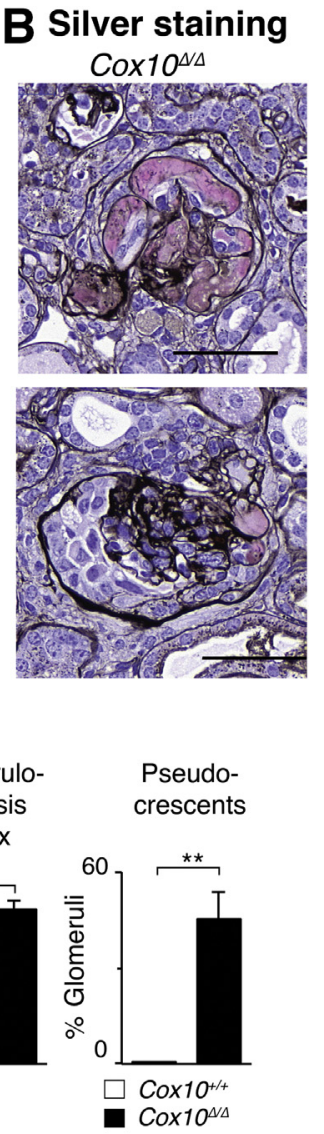

Figure 1 Cox10 deficiency in the nephron causes severe forms of focal segmental glomerulosclerosis. A and B: Representative photomicrographs taken from periodic acid-Schiff (PAS) stained kidney cortical sections of $\operatorname{Cox} 10^{4 / \Delta}$ (Six2$\mathrm{Cre}^{+} ; \mathrm{Cox} 10^{f / f l}$; knockout phenotype) and $\operatorname{Cox} 10^{+/+}$ (Six2-Cre ${ }^{-}$Cox10 ${ }^{f / f l}$; wild-type phenotype) mice (A) and methenamine silver (silver)-stained kidney cortical sections of $\mathrm{Cox}_{10^{\Delta / \Delta}}$ mice at 3 months of age (B). C: Evaluation of FSGS in $\operatorname{Cox} 10^{\Delta / \Delta}$ and $\operatorname{Cox} 10^{+/+}$ kidneys using an index system and based on the percentage of sclerotic glomeruli and glomeruli with crescent formation. Statistics analyzed using the $U$-test. D: Representative electron micrographs taken from glomeruli of $\operatorname{Cox} 10^{4 / \Delta}$ and $\operatorname{Cox} 10^{+/+}$kidneys. Arrows indicate podocyte foot processes. Data are expressed as means \pm SEM (C). $n=4$ to 9 (C). ${ }^{*} P \leq 0.05,{ }^{*} P \leq 0.01$. Scale bars: $50 \mu \mathrm{m}(\mathbf{A}$ and $\mathbf{B})$; $2 \mu \mathrm{m}$ (D).

\section{Electron microscopy}

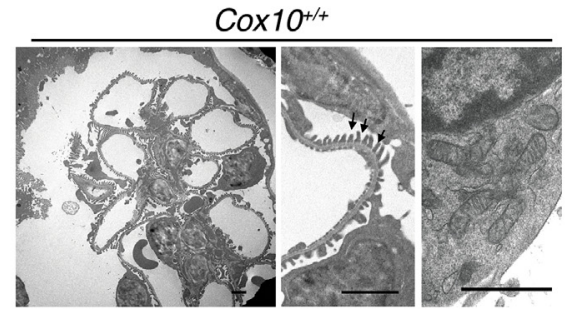

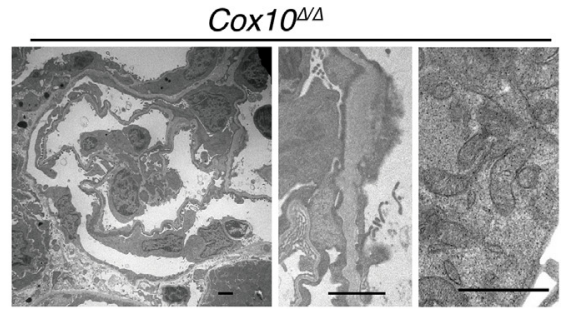

microscopy of glomeruli from $\operatorname{Cox} 10^{\Delta / \Delta}$ mice at 2.5 months of age showed typical features of a podocytopathy with extensive effacement of podocyte foot processes along the glomerular basement membrane and reduction of primary and secondary podocyte processes. In addition, mitochondria of remaining podocytes in sclerotic glomeruli of Cox $10^{\Delta / \Delta}$ mice showed morphologic changes characterized by increased diameter, decreased length, and partial loss of cristae (Figure 1D).

\section{Cox $10^{4 / \Delta}$ Mice Are Susceptible to Prenatal and Postnatal Lethality with Renal Failure}

While breeding mice, it was noticed that $\operatorname{Cox} 10^{\Delta / \Delta}$ mice have a shorter lifespan than WT littermates and are born at submendelian ratios. Hence, survival was first examined in 55 $\operatorname{Cox} 10^{\Delta / \Delta}$ mice, and the median survival time of $\operatorname{Cox} 10^{\Delta / \Delta}$ mice was found to be 38 days; all $\operatorname{Cox} 10^{4 / \Delta}$ mice that were analyzed died before 20 weeks of age (Figure 2A). In addition, Six2-Cre ${ }^{-I-} ; \operatorname{Cox}_{1} 0^{f / / f}$ mice were crossed to Six2$\mathrm{Cre}^{+/-} ; \mathrm{Cox}_{10} \mathrm{O}^{\mathrm{fl}+}$ mice to verify that the disruption of Cox10 in the nephron results in prenatal lethality. Mendelian ratios would predict equal proportions for all possible ge-

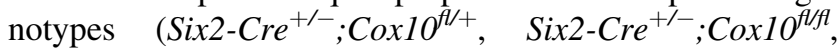
$\mathrm{Six2}-\mathrm{Cre}^{-/-} ; \mathrm{Cox} 10^{f / /+}$, and Six2-Cre $\left.{ }^{-/-} ; \operatorname{Cox} 10^{f / f f}\right)$. However, the number of $\operatorname{Cox} 10^{4 / 4}$ mice was only 4 of 37 pups obtained from five litters with this breeding strategy, which was a submendelian ratio (Figure 2B), suggesting that a substantial proportion of $\operatorname{Cox} 10^{\Delta / \Delta}$ mice die in utero. These results predict that disease occurs in the early development of the mouse and should be detectable early after birth. Body weights of male $\operatorname{Cox} 10^{4 / \Delta}$ mice surviving beyond the first 3 months showed a $25 \%$ reduction at 2 months and a $37 \%$ reduction at 3 months compared with WT littermates (Figure 2B). The same tendency was observed in female groups (Supplemental Figure S1B). At 2 to 3 months, 


\section{A Lethality}
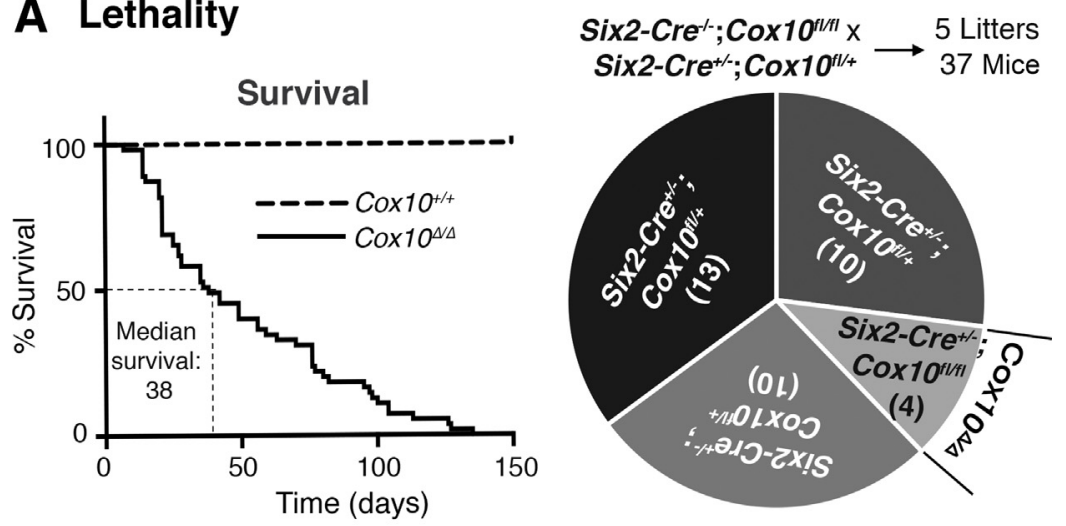

B Body weight

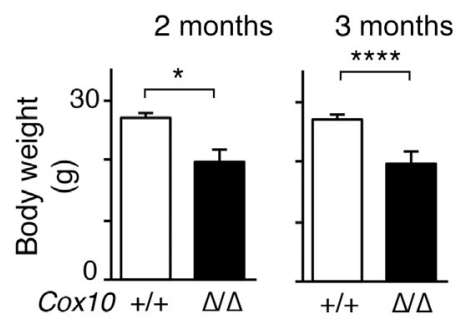

\section{Kidney weight}
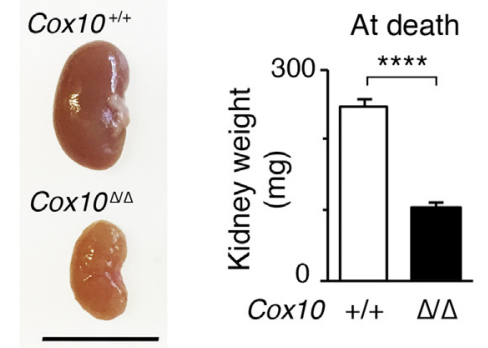

Figure 2 Cox10 deficiency in the nephron produces prenatal and postnatal lethality with renal failure. A: Left panel: Kaplan-Meier curve showing the survival of $\operatorname{Cox} 10^{\Delta / \Delta}$ compared with $\operatorname{Cox} 10^{+/+}$mice. Right panel: Breeding scheme to test Cox10 deficiency-associated embryogenic lethality and a pie chart showing genotype distribution of the offspring. B: Body weights of male Cox $10^{\Delta / \Delta}$ compared with $\mathrm{Cox} 10^{+/+}$mice at 2 and 3 months of age. C: Representative photomicrographs and graphs showing kidney weights of male $\operatorname{Cox} 10^{4 / \Delta}$ compared with $\operatorname{Cox} 10^{+/+}$mice at the time of natural death and euthanasia. D: Assessment of kidney function of $\operatorname{Cox} 10^{\Delta / \Delta}$ and $\operatorname{Cox} 10^{+/+}$mice by serum creatinine, blood urea nitrogen (BUN), and urinary albumin levels. Statistics analyzed using the $U$-test. Data are expressed as means \pm SEM (B-D). $n=55$ (A, right panel); $n=4$ mice aged 2 months (B); $n=7$ to 11 mice aged 3 months (B); $n=8$ (C); $n=11$ (D). ${ }^{*} P \leq 0.05$, $* * * * P \leq 0.0001$. Scale bar $=1 \mathrm{~cm}(\mathbf{C})$.

\section{Kidney function}
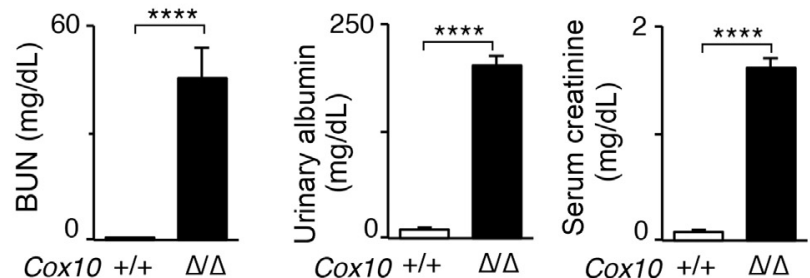

kidney weight and volume were markedly decreased in $\operatorname{Cox} 10^{\Delta / \Delta}$ mice compared with age-matched controls (Figure 2C and Supplemental Figure S1C). Consistent with the severity of glomerulosclerosis, $\operatorname{Cox} 10^{4 / \Delta}$ mice showed impaired kidney function with albuminuria, as evaluated by the levels of serum creatinine, blood urea nitrogen, urinary albumin, and urinary albumin/creatinine ratio compared with age- and sex-matched mice (Figure 2D and Supplemental Figure S1D).

\section{Cox $10^{4 / \Delta}$ Mice Develop Tubulointerstitial Damage and Fibrosis}

Human FSGS is frequently associated with severe tubulointerstitial disease. ${ }^{9}$ Although the precise drivers of nonglomerular disease in FSGS are not fully elucidated, prevailing models suggest that this is predominantly secondary to podocyte disease..$^{9,52}$ Nevertheless, the causes of podocyte disease may also simultaneously cause tubular disease, as could be the case when mitochondrial function is disrupted. In $\operatorname{Cox} 10^{\Delta / \Delta}$ mice, in which COX10 is deleted in podocytes as well as tubules, severe tubular pathology was seen at 2.5 to 3 months of age. A considerable number of renal tubules in the outer medulla of $\operatorname{Cox} 10^{\Delta / \Delta}$ kidney were atrophic $(30.0 \pm 2.0$ versus $5.1 \pm 0.6$ tubules per microscopic field in $\operatorname{Cox}_{10^{+/+}}$kidney) and dilated (7.9 \pm 1.4 versus $1.3 \pm 0.2$ tubules per microscopic field in $\operatorname{Cox} 10^{+/+}$ kidney). A total of $5.3 \% \pm 0.4 \%$ of renal tubules per microscopic field (versus $0.1 \% \pm 0.0 \%$ tubules in Cox $10^{+/+}$ kidney) showed casts in $\operatorname{Cox} 10^{\Delta / \Delta}$ kidney (Figure 3A). Interstitial fibrosis is a hallmark of tubulointerstitial disease $^{53}$ and represents a common pathway leading to progression of chronic kidney disease. ${ }^{54}$ Therefore, interstitial fibrosis was studied in kidneys of $\operatorname{Cox} 10^{4 / \Delta}$ mice at 2.5 to 3 months of age by two different methods, picrosirius red staining and immunofluorescence staining of $\alpha$-smooth muscle actin, a marker for activated fibroblasts. Large areas in the cortex and outer medulla of $\operatorname{Cox} 10^{\Delta / \Delta}$ kidney were found to be fibrotic. Fibrotic lesions were especially prominent in the periglomerular region and cortical interstitium (Figure 3, B and C). For evaluation of tubular injury, expression of the tubular injury marker Kim-1 was 


\section{A Pathology}

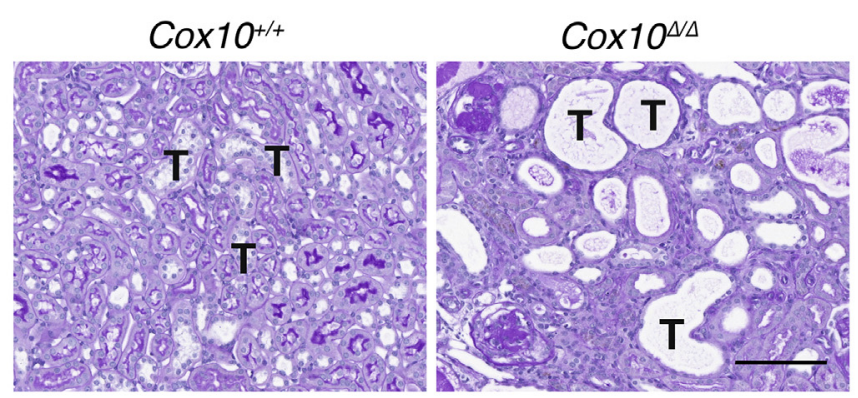

Atrophic Dilated tubules tubules

Casts

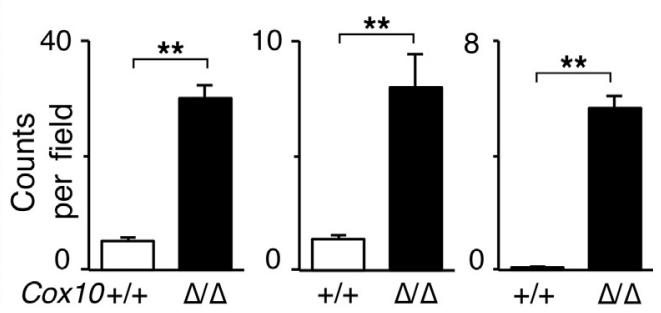

B Fibrosis
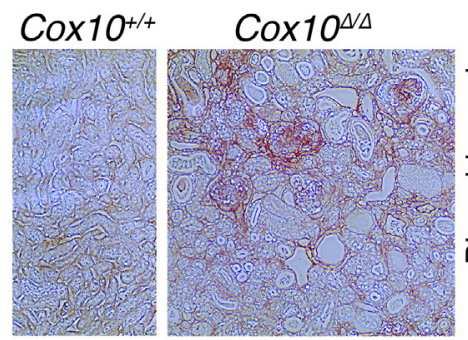

Picrosirius red

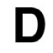

Tubular injury

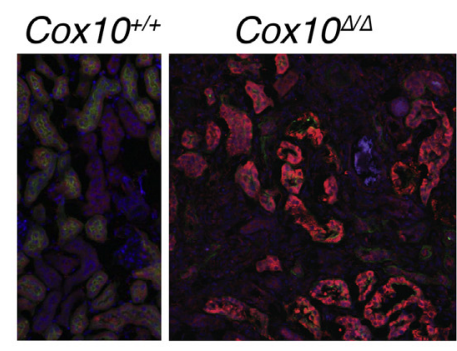

LTL KIM-1 DAPI
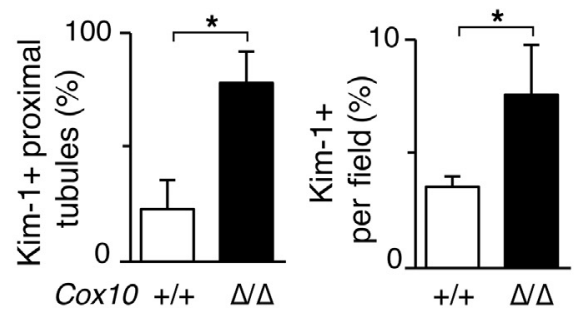

\section{Activated fibroblasts}
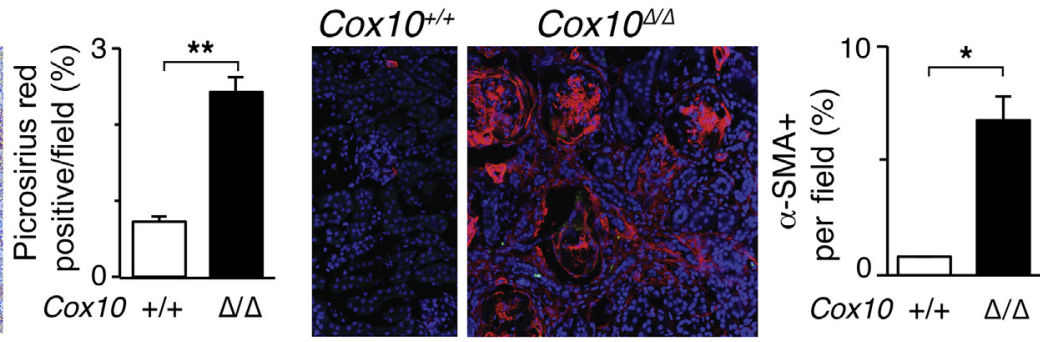

$\alpha$-SMA DAPI

E Apoptosis

Cox10 $1+4$

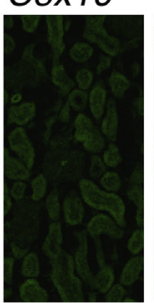

$\operatorname{Cox} 10^{\Delta \Delta}$

Caspase-3 DAPI

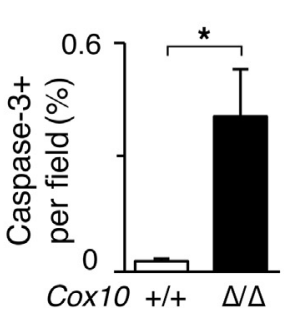

\section{F Macrophage infiltration}

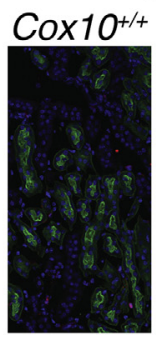

$\operatorname{Cox} 10^{\Delta / \Delta}$

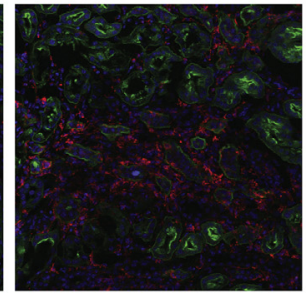

LTL F4/80 DAPI

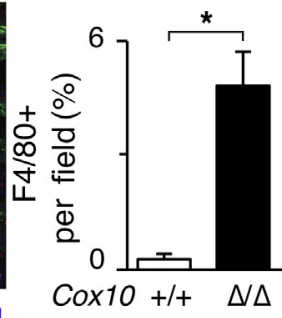

Figure 3 Cox10 deficiency in the nephron leads to tubulointerstitial damage. A: Representative photomicrographs taken from periodic acid-Schiff (PAS) stained kidney sections of $\operatorname{Cox} 10^{4 / \Delta}$ and $\operatorname{Cox} 10^{+/+}$mice at 3 months of age. Using PAS-stained kidney sections, tubular damage was evaluated on the basis of the percentage of dilated, atrophic tubules (T); tubules were in $\operatorname{Cox} 10^{4 / 4}$ compared with $\operatorname{Cox} 10^{+/+}$kidney. B-F: Evaluation of fibrosis (B), activated fibroblasts (C), proximal tubular injury (D), apoptosis (E), and macrophage infiltration in kidneys (F) from $\operatorname{Cox} 10^{\Delta / \Delta}$ and $\operatorname{Cox} 10^{+/+}$mice at 3 months of age using immunostaining. All statistics analyzed using the $U$-test. Data are expressed as means \pm SEM $(\mathbf{A}-\mathbf{F}) . n=4$ to $9(\mathbf{A}$ and $\mathbf{B}) ; n=3(\mathbf{C}-\mathbf{F}) .{ }^{*} P \leq 0.05,{ }^{* *} P \leq 0.01$. Scale bar $=$ $100 \mu \mathrm{m}(\mathbf{A})$. Original magnification, $\times 20(\mathbf{B}-\mathbf{F})$. KIM-1, kidney injury molecule-1; LTL, lotus tetragonolobus lectin; $\alpha$-SMA, $\alpha$-smooth muscle actin.

studied. ${ }^{55}$ Kim-1 is up-regulated in proximal tubules after tubular injury and fibrosis. ${ }^{56}$ To colocalize Kim-1 to proximal tubules, fluorescently tagged LTL was applied to detect proximal tubules. In $\operatorname{Cox} 10^{\Delta / \Delta}$ kidneys at 2.5 to 3 months of age, most $\mathrm{LTL}^{+}$proximal tubules coexpressed Kim-1 (Figure 3D). In addition, increased expression of cleaved caspase-3, an indicator of cellular apoptosis, was seen in renal tubules of $\operatorname{Cox} 10^{4 / \Delta}$ kidneys (Figure 3E). Next, the kidneys from $\operatorname{Cox} 10^{\Delta / \Delta}$ and $\operatorname{Cox} 10^{+/+}$mice were examined for the magnitude of macrophage infiltration. Macrophages are found in normal kidney and in increased numbers in kidney injury. When inflammation occurs, the pool of 
A
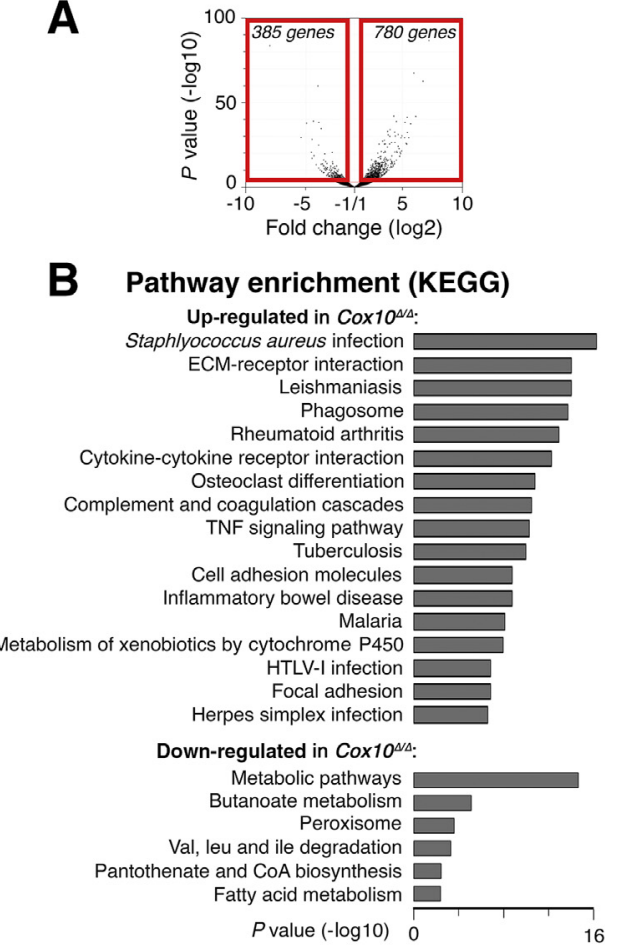

C mtDNA-encoded genes

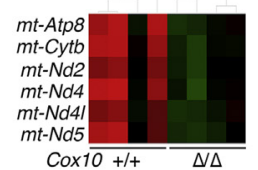

D Nephrotoxicity genes (IPA)

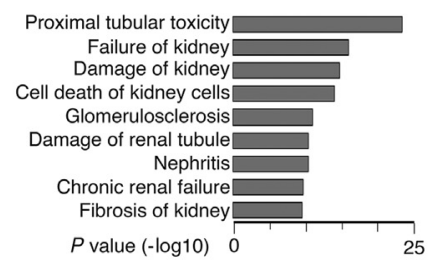

E Interferome analysis

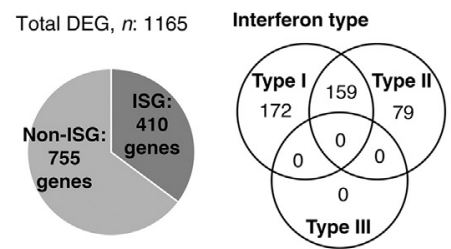

F Total ISG

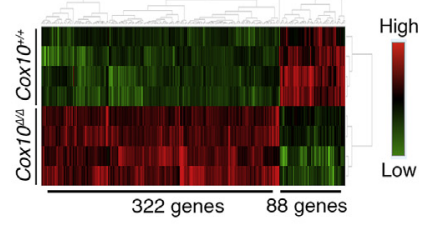

G Protein

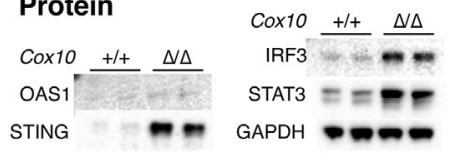

tissue-resident and monocyte-derived macrophages is expanded, being provided with growth factors required for activation, survival, and proliferation. ${ }^{57,58}$ In $\operatorname{Cox} 10^{\Delta / \Delta}$ kidneys, increased numbers of macrophages were present in patches, indicative of ongoing or nonresolving inflammation (Figure 3F).

\section{Cox $10^{\Delta / \Delta}$ Kidneys Up-Regulate Nephrotoxicity- and Interferon-Stimulated Genes}

To identify genes differentially regulated in $\operatorname{Cox} 10^{4 / \Delta}$ versus $\operatorname{Cox} 10^{+/+}$kidneys and investigate molecular pathways being activated by mitochondrial dysfunction, global transcriptional profiling analysis of sequences mapped to the mouse transcriptome was performed after RNA sequencing of whole-kidney tissue from $\operatorname{Cox} 10^{4 / 4}$ and $\operatorname{Cox} 10^{+/+}$mice at 2.5 to 3 months of age. As expected, principal component analysis of the data set separated the samples into two groups: $\operatorname{Cox} 10^{\Delta / \Delta}$ and $\operatorname{Cox} 10^{+/+}$(Supplemental Figure S1E). A total of 780 genes were found to be significantly up-regulated, and 385 genes were significantly down-regulated, in $\operatorname{Cox} 10^{4 / \Delta}$ kidneys (Figure $4 \mathrm{~A}$ and Supplemental Table S1). The differentially expressed genes showed changes consistent with tubulointerstitial disease, with up-regulation of innate immunity, complement, phagocytosis, and extracellular matrix receptor interaction pathways (Figure 4B). In addition, the genes were enriched for viral signaling pathways, including human T-lymphotropic virus and herpes simplex virus (Figure 4B). Strikingly, there was marked down-regulation of lipid and fatty acid metabolism consistent with a loss of mitochondrial function, as detected by loss of metabolic pathways, butanoate metabolism, and peroxisome and CoA biosynthesis (Figure 4B and Supplemental Figure S2). Unexpectedly, there was also marked loss of multiple transcripts encoded from mtDNA (Figure 4C), in keeping with a high degree of loss of mitochondrial function. In addition, Ingenuity

Figure 4 Cox10 deficiency in the nephron up-regulates nephrotoxicity genes and interferon-stimulated genes (ISGs). Comparison of gene expression profile in $\operatorname{Cox} 10^{\Delta / \Delta}$ versus $\operatorname{Cox} 10^{+/+}$kidneys using RNA sequencing. A: A volcano plot visualizing differentially expressed genes in $\operatorname{Cox} 10^{\Delta / \Delta}$ versus $\operatorname{Cox} 10^{+/+}$kidneys with fold changes significantly $(P<0.001)>1.4$. Significance versus fold change is plotted on the $y$ and $x$ axes, respectively. B: Pathway enrichment analysis using DAVID. C: A heat map featuring differently expressed mtDNA-encoded genes. D: Clustering and annotation of differentially expressed genes associated with nephrotoxicity using Ingenuity Pathway Analysis (IPA) Software version 01-10. E: Identification of ISGs among differentially expressed genes using INTERFEROME version 2.01. F: Expression and clustering of all differentially expressed ISGs graphically presented as a heat map. G: Western blot analysis for selected ISGs in $\operatorname{Cox} 10^{4 / \Delta}$ versus Cox10 $0^{+/+}$kidneys. $n=4$ $(\mathbf{A}-\mathbf{F})$. DEG, differentially expressed genes; ECM, extracellular matrix; GAPDH, glyceraldehyde-3-phosphate dehydrogenase; HTLV-1, human Tlymphotropic virus; IRF, interferon regulatory factor; KEGG, Kyoto Encyclopedia of Genes and Genomes; OAS, 2'-5'-oligoadenylate synthetase 1; STING, stimulator of interferon genes; TNF, tumor necrosis factor. 
A Scheme

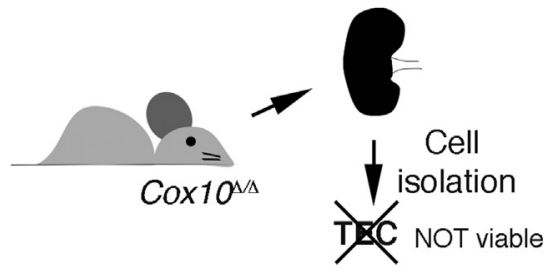

C Mitochondrial function

Mitochondrial respiration

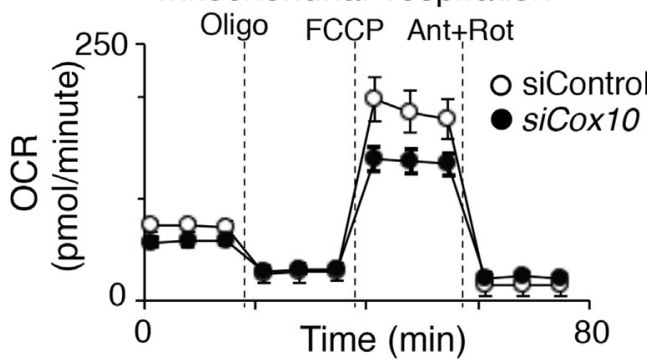

B Cox10 knockdown

Cox10

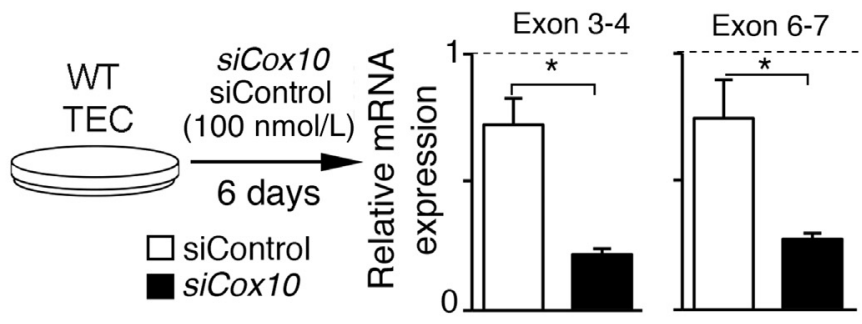

D

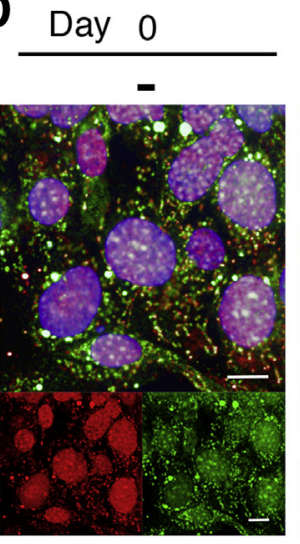

2

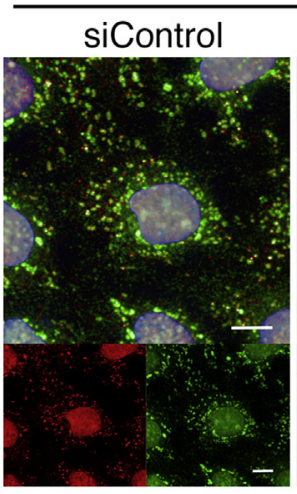

Basal Maximal ATP respiration respiration production

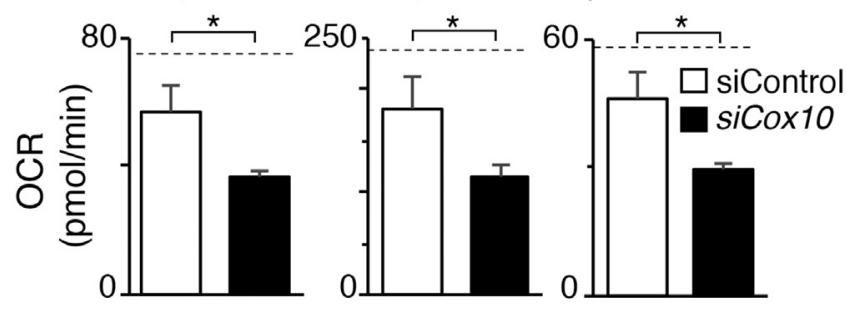

$\mathbf{E}$

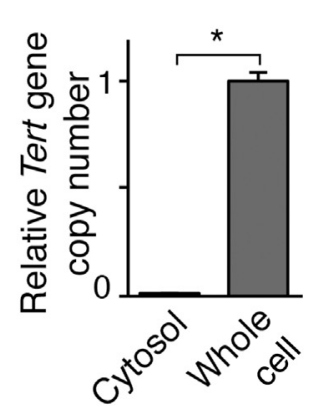

F

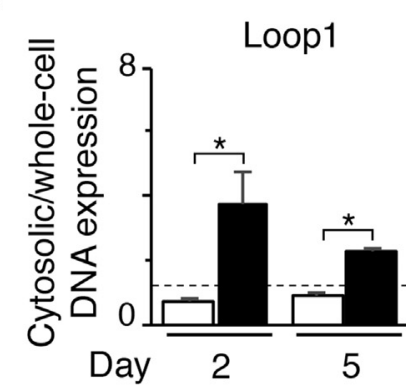

$\operatorname{siC} 0 \times 10$
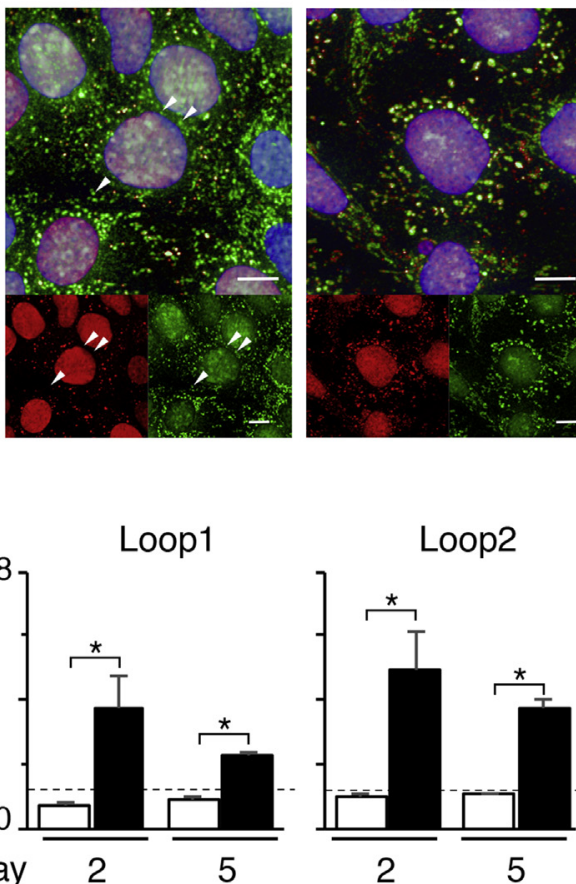

5
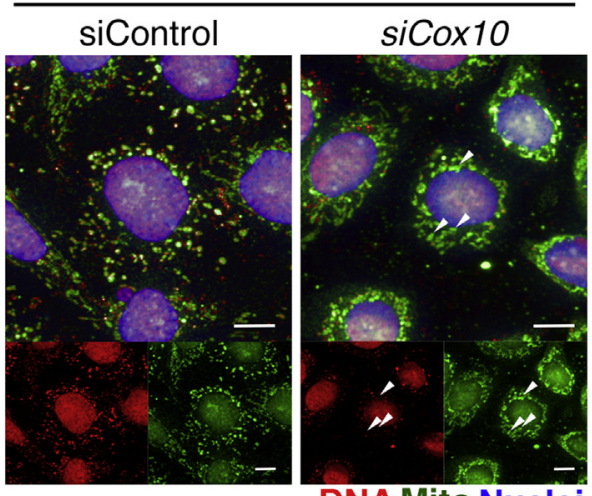

DNA Mito Nuclei

\section{G}

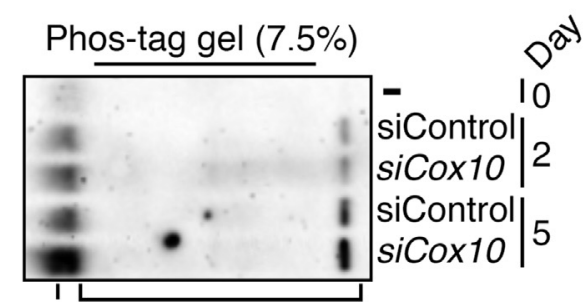

STING pSTING

H

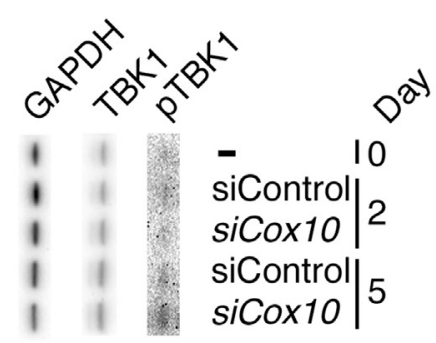


Pathway Analysis showed strong enrichment for genes involved in kidney failure, consistent with the histologic and clinical parameters described in Figures 1, 2, and 3 and summarized in Figure 4D. Because there was strong enrichment for viral-induced signaling pathways, and a notable increase in certain interferon response genes, the gene set was studied, and strong enrichment for activation of ISGs was found. Further analysis of all of the differentially expressed genes indicated that $>30 \%$ were ISGs, and a secondary analysis of these ISGs indicated that most (80\%) were type I interferon response genes (Figure 4, E and F, and Supplemental Table S2). The up-regulation of the ISGs, OAS1, STING (encoded by Tmem173), and the interferon-inducing and interferon-induced transcription factors, IRF1 and STAT3, was validated in $\operatorname{Cox} 10^{\Delta / \Delta}$ versus $\mathrm{Cox}_{10^{+/+}}$kidneys at protein levels using Western blot analysis (Figure 4G). This strong type I interferon signature was unexpected but is consistent with mitochondrial dysfunction being causally linked to type I interferon pathway activation, similar to the effects of viral infection and as seen in certain autoimmune diseases, such as systemic lupus erythematosis. ${ }^{59}$ Cell death-associated genes were also detected (Supplemental Figure S1F). Because cell death and release of damage-associated molecular patterns can cause inflammation, the impact of mitochondrial dysfunction on the innate immune response was studied using in vitro approaches.

\section{Cox10 Ablation Triggers the Release of mtDNA into the Cytosol and Activates the Intracellular DNA Sensor STING}

To study the impact of mitochondrial dysfunction on the cellular level, an in vitro approach was used. PTECs $\left(\mathrm{LTL}^{+}\right)$ or TECs $\left(\mathrm{EpCAM}^{+}\right)$were isolated from kidneys of Cox $10^{4 / \Delta}$ mice to obtain Cox10-deficient PTECs and TECs. However, they were not viable in vitro, emphasizing the profound impact of Cox10 deletion on epithelial cell health (Figure 5A). Instead, PTECs or TECs from wild-type mice were isolated and Cox10 expression was silenced in primary cultures of these cells by delivering exogenous siRNA to primary cell cultures (Figure 5A and Supplemental Figure S3A). TECs transfected with Cox10 siRNA (siCox10) reduced Cox10 transcripts by 50\% to $75 \%$ compared with untreated cells, and they were reduced by approximately 50\% compared with TECs transfected with control siRNA at days 2 and 6 of transfection, respectively (Figure 5B and Supplemental Figure S4, A and B). Cox10 silencing in PTECs was as efficient as in TECs (Cox10 mRNA reduction by $70 \%$ to $85 \%$ ). Unexpectedly, Cox 10 mRNA was also diminished in control PTECs but to a much lesser extent than in Cox10-silenced PTECs, suggesting PTECs are sensitive to siRNA transfection, causing transient down-regulation of mitochondrial biogenesis (Supplemental Figure S3B). More important, no differences in cell viability between Cox10-silenced and control TECs through 5 days were observed (Supplemental Figure S5A). Next, changes in the mitochondrial function in TECs after Cox10 silencing were studied (Figure 5C). The oxygen consumption rate of Cox10-silenced TECs was compared with control TECs before and after serial additions of oligomycin (an inhibitor of ATP synthase), carbonyl cyanidep-trifluoromethoxyphenylhydrazone (an uncoupling ionophore), and rotenone with antimycin A (blocking agents for the complexes I and III of the electron transport chain, respectively). Cox10-silenced TECs had reduced basal respiration, maximal respiratory capacity, and mitochondrial ATP production compared with controls (Figure 5C). In addition, reserve respiration capacity, which is calculated as the difference between maximal respiratory capacity and basal respiration, was reduced by $22.1 \% \pm 15.1 \%$. Taken together, these data showed that loss of COX10 affects mitochondrial oxidative phosphorylation within 5 days. The quantity of total ATP produced by Cox10-silenced TECs was also studied. Similarly, ATP production was decreased at day 5 after silencing (Supplemental Figure S5B). Next, MMP was assessed in Cox10-silenced TECs. MMP was modestly reduced by approximately $12 \%$ in Cox10-silenced versus control TECs at day 6 after transfection (Supplemental Figure S5C). This result is consistent with the effects of Cox10 silencing on mitochondrial respiration (Figure 5C), but the more modest reduction of MMP after Cox10 silencing may result from compensatory mechanisms exerted by complexes I and III, while complex IV is failing. In addition to the decline of ATP production, Cox10 silencing led to a subsequent reduction of mtDNA content. Previously, Diaz et $\mathrm{al}^{60}$ reported that human fibroblasts displayed abnormal mitochondrial morphology with rounder and larger appearance after COX10 deletion. In line with those reports, changes were detected in mitochondrial

Figure 5 Cox10 silencing in kidney tubular epithelial cells (TECS) results in mitochondrial dysfunction and release of mtDNA into the cytosol and activates stimulator of interferon genes (STING). A: Schematic representation: TECs isolated from Cox10 ${ }^{\Delta / \Delta}$ mice are not viable in vitro. Thus, Cox10-targeted (siCox10) and control (siControl) siRNAs were introduced into cultured wild-type (WT) TECs by transfection (each at a final concentration of $100 \mathrm{nmol} / \mathrm{L}$ ) to study the role of Cox10 in TECs. B: At day 6 of transfection, cells were harvested and analyzed for Cox10 mRNA expression. C: The oxygen consumption rate (0CR) was measured at baseline and in response to oligomycin (Oligo), carbonyl cyanide-p-trifluoromethoxyphenylhydrazone (FCCP), and antimycin plus rotenone (Ant + Rot) using the Seahorse XFe extracellular flux analyzer. D: Confocal microscopy images were taken from TECs stained with anti-DNA (DNA) and anti-superoxide dismutase (Mito) at days 2 and 5 of transfection. Arrowheads indicate mitochondria not colocalizing with DNA staining. E: Nuclear-encoded Tert gene expression was quantitated via real-time quantitative PCR in cytosolic and whole-cell extracts of untreated TECs. F: Cytosolic mtDNA content in transfected TECs. G and H: Western blot analysis for phosphorylation of STING (G) and TANK-binding kinase-1 (TBK1; $\mathbf{H})$ in transfected TECs. Dashed lines indicate untreated cells (B, C, and F). Data are expressed as means \pm SEM (B, C, E, and F). $n=3$ to 4 (B, C, E, and F). ${ }^{\star} P \leq 0.05$ (U-test). Scale bars $=10 \mu \mathrm{m}(\mathbf{D})$. Original magnification, $\times 63$ (D). GAPDH, glyceraldehyde-3-phosphate dehydrogenase. 


\section{A Oxidative stress}

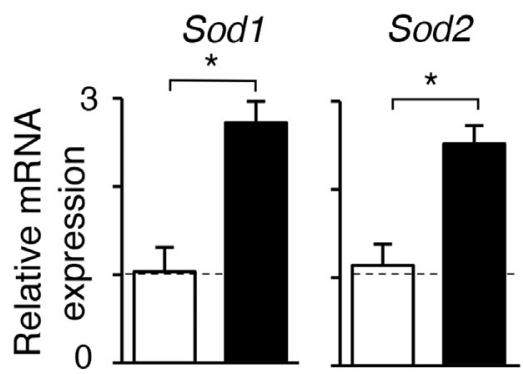

\section{B Apoptosis}

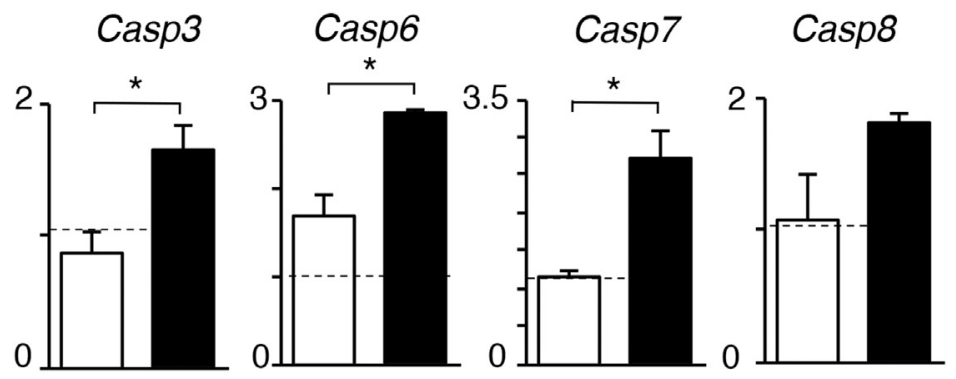

\section{Inflammation}
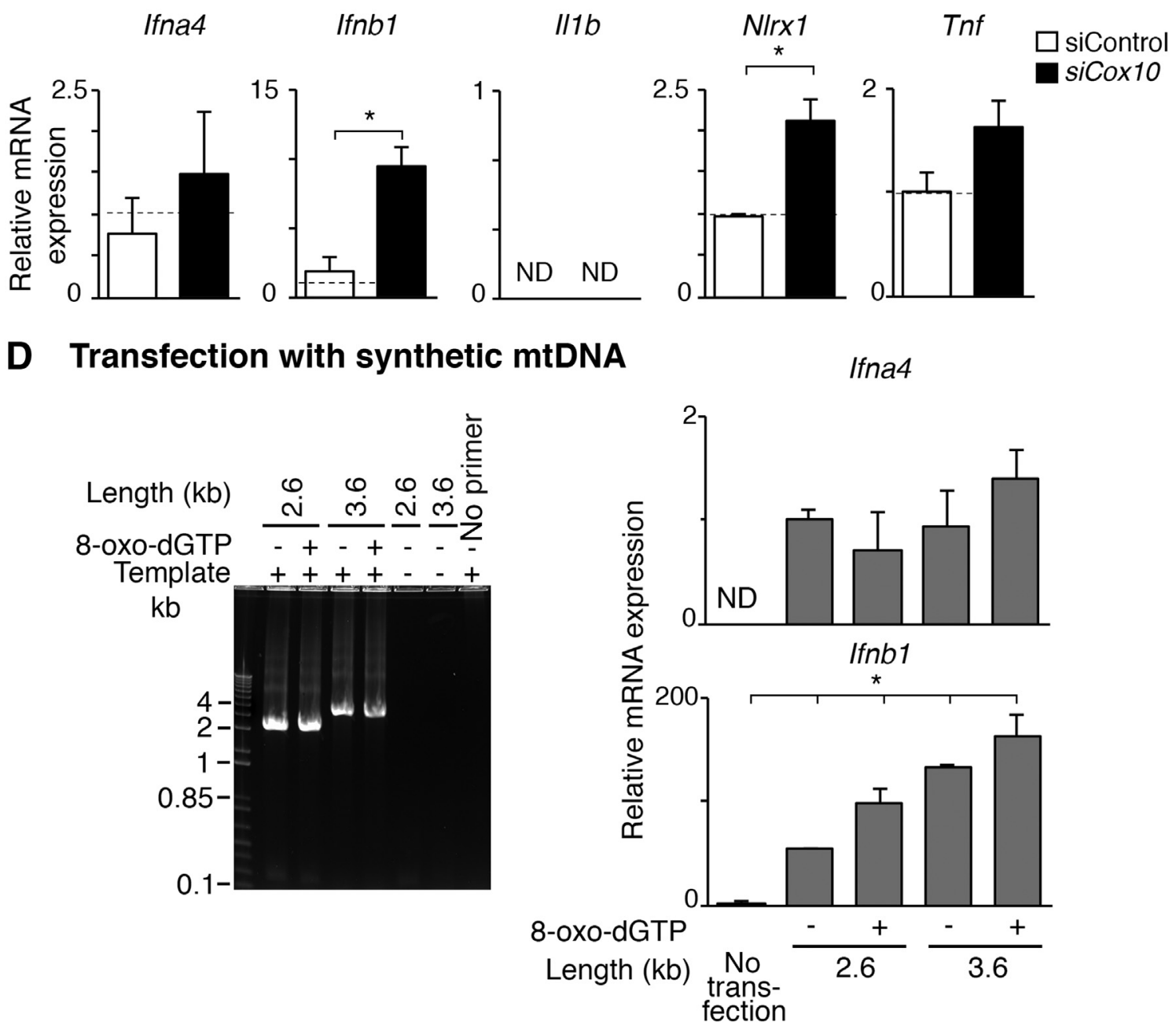

Figure 6 Cox10 silencing or introduction of mtDNA into the cytosol up-regulates apoptotic, proinflammatory, and interferon transcripts in tubular epithelial cells (TECs). Wild-type TECs were transfected with $100 \mathrm{nmol} / \mathrm{L}$ of siCox10 and control siRNA (siControl). A-C: At day 6 after silencing, cells were harvested and analyzed for mRNA expression of oxidative stress-related (A), apoptosis-related (B), and proinflammatory (C) genes. Dashed lines indicate untreated cells. D: Transcriptional expression of Ifna4 and Ifnb1 in TECs transfected with 2.6- or 3.6-kb fragments of synthesized oxidized mtDNA at 4 hours. Data are expressed as means \pm SEM (A-D). $n=3$ to 4 (A-D). ${ }^{*} P \leq 0.05$ (U-test). ND, not detected.

morphology and location at day 5 after Cox10 silencing: the mitochondria appeared swollen and more concentrated within the perinuclear region (Figure 5D). Moreover, individual mitochondria lacking mtDNA could be detected only after Cox10 silencing. To determine whether the loss of
mtDNA was attributable to release into the cytosol, extramitochondrial mtDNA was assessed in CoxlO-silenced versus control TECs. Pure cytosolic extracts did not contain detectable nuclear DNA, as expected (Figure 5E and Supplemental Figure S6). Those cytosolic extracts were 


\section{A In vitro ISG expression}

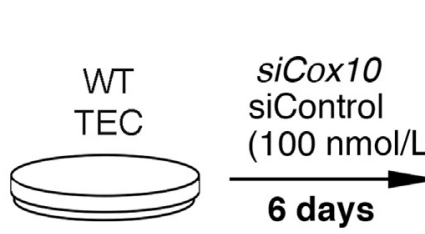

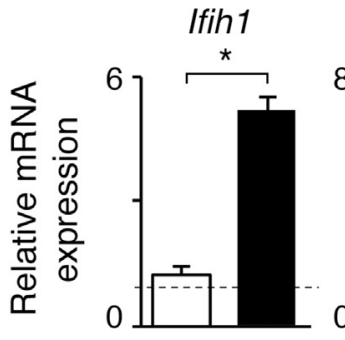
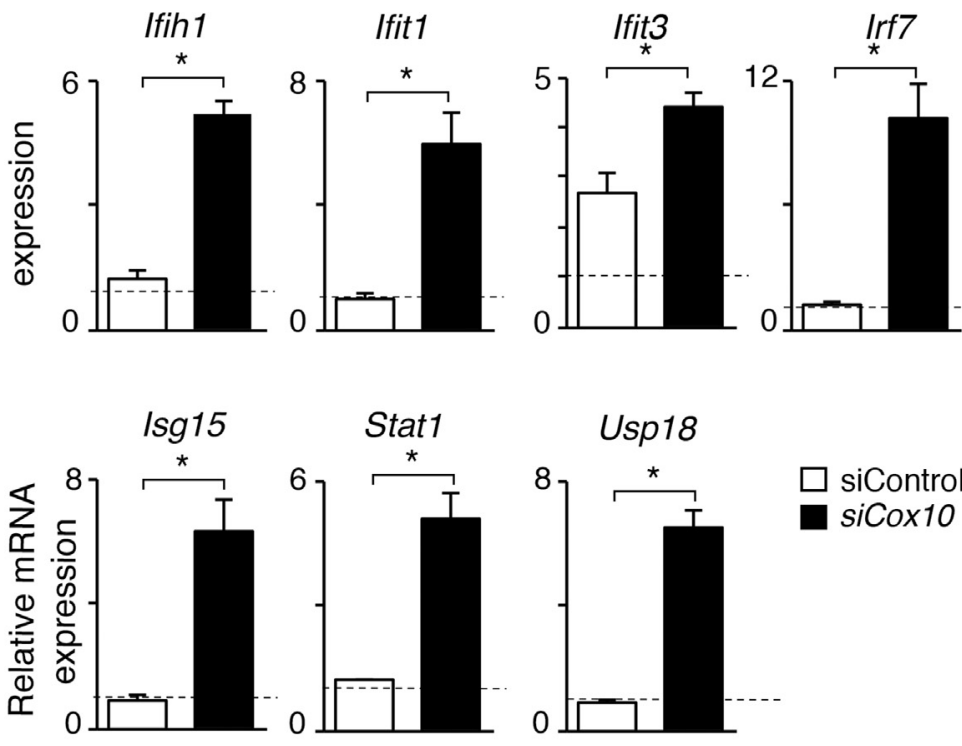

Usp18

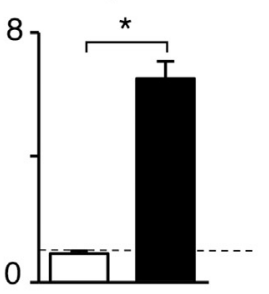

$D d x 58$

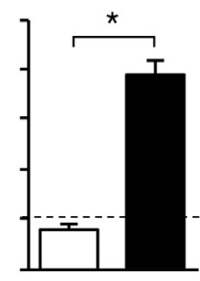

\section{B In vivo ISG expression}
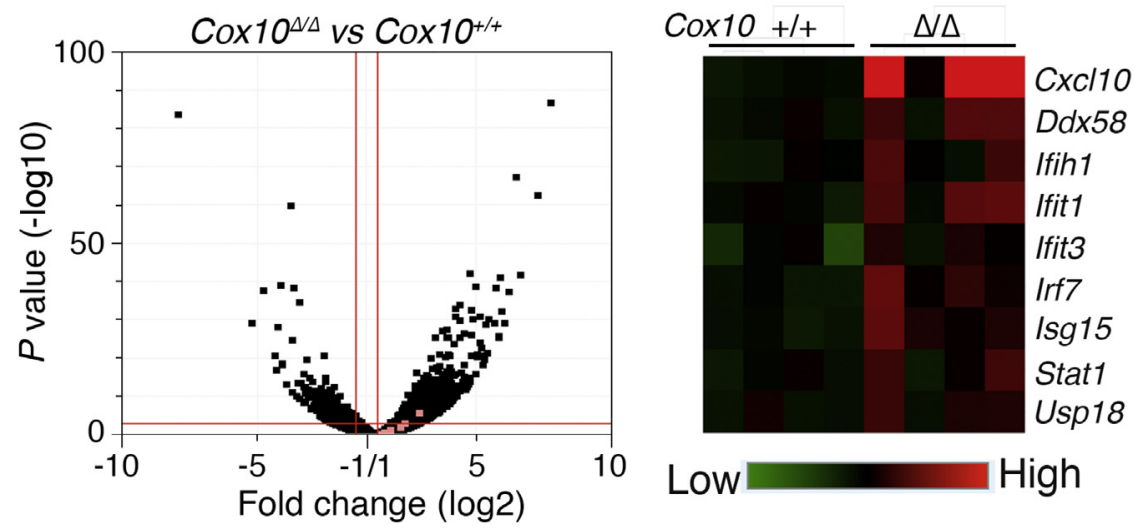

analyzed for mtDNA content. After silencing of Cox10, a fourfold to fivefold and a threefold to fourfold increase of specific mtDNA fragments from the Dloop regulatory region was detected at days 2 and 5 of transfection, respectively; this was consistent with modest liberation of mtDNA into the cytosol in response to loss of CoxlO (Figure 5F). Next, it was evaluated whether the presence of mtDNA in the cytosol could activate an important DNA sensor, STING, which is highly up-regulated in the $\operatorname{Cox} 10^{\Delta / \Delta}$
Figure 7 Cox10 silencing elevates the expression levels of interferon-stimulated genes (ISGs) in tubular epithelial cells (TECs). A: Wildtype (WT) TECs transfected with $100 \mathrm{nmol} / \mathrm{L}$ of siCox10 and control siRNA (siControl). At day 6 of transfection, cells were harvested and analyzed for mRNA expression of differentially expressed ISGs. Dashed lines indicate untreated cells. B: Comparison of ISG expression in $\operatorname{Cox} 10^{\Delta / \Delta}$ versus Cox $10^{+/+}$kidneys using RNA sequencing. Select ISGs with fold changes $>1.4$ are highlighted in red in the volcano plot (left panel) and visualized in a heat map (right panel). Data are expressed as means $\pm \operatorname{SEM}($ A). $n=3$ (A); $n=4$ (B). ${ }^{*} P \leq 0.05$ (U-test). 


\section{Cox10 Ablation Induces Up-Regulation of 0xidative Stress and Pro-Apoptotic Genes}

Because Cox10 silencing causes mitochondrial dysfunction and triggers the release of mtDNA in vitro, it was next examined whether Cox10 ablation induces oxidative stress by detecting a compensatory expression of the cytosolic and mitochondrial superoxide dismutases Sod1 and Sod2. Both genes are up-regulated more than twofold in CoxlO-silenced TECs at 6 days of transfection (Figure 6A). When functional enrichment analysis of differentially expressed genes associated with renal necrosis/cell death was performed in $\operatorname{Cox} 10^{\Delta / \Delta}$ versus $\operatorname{Cox} 10^{+/+}$kidneys, pathways involved in apoptosis of TECs, podocytes, and mesangial cells and in the necrosis of TECs were identified (Supplemental Figure S1E). Hence, it was examined whether mRNA transcripts of caspases are elevated in TECs after Cox10 silencing. Six days after transfection, silencing of Cox10 led to elevated expression of executioner caspases, Casp3, Casp6, and Casp7, as well as the initiator caspase, $\operatorname{Casp}^{61}$ (Figure 6B). Neither caspases nor the oxidative stress indicators, Sod1 and Sod2, were elevated in Cox10-silenced TECs at 2 days of transfection (Supplemental Figure S4, C and D). However, both TECs and PTECs up-regulated Sod1, Sod2 (Supplemental Figure S3C), and Casp3, Casp6, and Casp8 at day 6 after Cox10 silencing. Unlike TECs, Cox10 silencing in PTECs caused an early increased expression of Sod1, Casp3, and Casp 8 within 2 days but did not up-regulate Casp7 (Supplemental Figure S3, D and E).

\section{Cox10 Ablation Induces Interferon Response}

These results support a model in which deletion of COX10 in TECs causes mitochondrial dysfunction, leading to the release of mtDNA into the cytosol, with immunogenic and inflammatory properties, only subsequently initiating cell death pathways. ${ }^{20,30,51}$ This may provide an explanation for the prominent type I interferon signature in $\operatorname{Cox} 10^{\Delta / \Delta} \mathrm{kid}$ neys. To test this hypothesis, transcript levels of proinflammatory cytokines, including interferon genes, Ifna4 and Ifnbl, and other selected cytokines implicated in the pathogenesis of chronic kidney diseases, $I l l b,{ }^{62} N \operatorname{lr} x 1,{ }^{63-65}$ and Tnfa, ${ }^{66,67}$ were assessed in Cox10-silenced PTECs and TECs. Compared with control-treated cells, those with Cox10 silencing had persistent elevation of interferons, particularly interferon $\beta$ (Ifnbl), as well as modest elevations of Nlrxl and Tnfa (Figure 6C). Treatment of epithelial cells with siRNA induces a sequence nonspecific immune response. siRNAs are double-stranded RNAs and may serve as low-level agonists for pattern recognition receptors. However, knowing that siRNA-mediated interferon response is transient and resolves, it was found that the transcriptional expression of Ifna4 and Ifnbl in TECs increased markedly at day 2 , but decreased to baseline levels by day 6 (Figure 6C and Supplemental Figure S4E).

To test directly whether cytosolic mtDNA can provoke an interferon response, 2.6- and 3.6-kb fragments of mtDNA were synthesized. In one set of experiments, oxo-GTP was incorporated instead of GTP to generate oxidized mtDNA. Transfection of mtDNA into TECs caused a marked increase in Ifnbl transcripts and a smaller increase in Ifna4 transcripts. In the case of Ifnbl responses, the oxidized forms of mtDNA had a more marked effect on Ifnbl transcription (Figure 6D).

Next, the expression of genes that are activated in response to type I interferons (alias ISGs), previously identified as genes activated by mtDNA, was examined. ${ }^{20}$ Consistent with elevated production of interferons in response to Cox10 silencing, increased expression of ISGs was observed, including Cxcl10, Ddx58, Ifih1, Ifit1, Ifit3, Irf7, Is 15, Stat1, and Usp18, in Cox10-silenced TECs at day 6 of transfection (Figure 7A). Accordingly, these ISGs were found to be upregulated in $\operatorname{Cox} 10^{\Delta / \Delta}$ versus $\operatorname{Cox} 10^{+/+}$kidneys at 2.5 to 3 months of age, significantly or by trend (Figure 7B). Therefore, the in vitro results are consistent with a model in which Cox10 ablation leads to mitochondrial dysfunction, leading to interferon production and sensitization of kidney epithelial cells to increased interferon responses.

Taken together, we have identified a novel mechanism, which may contribute to FSGS pathogenesis. The data suggest that release of mtDNA into the cytosol is a mechanism inducing innate immune activation in podocytes and epithelial cells upstream of cell death. Cell death may result in release of damage-associated molecular patterns, further activating innate immune responses. Therefore, mtDNA release is one possible mechanism driving pathogenesis in FSGS caused by mitochondrial disease.

\section{Discussion}

These studies unequivocally demonstrate that loss of COX10, a cofactor of COX-IV in the electron transport chain, is sufficient to cause severe FSGS and tubulointerstitial disease. RNA sequencing of whole kidneys identified a strong interferon response to loss of COX10. The data link COX10 deficiency to mitochondrial dysfunction, leading, in turn, to leakage of mtDNA into cellular cytosol, which directly activates an interferon response and initiates an inflammatory cascade. These cascades are mediated by intracellular DNA sensor proteins, including STING.

An increasing number of mutations in mtDNA or in nuclear genes encoding critical mitochondrial proteins, including COX-IV proteins, have been documented to be causative in forms of FSGS and tubulointerstitial diseases. Herein, the dysfunction of the mitochondrial electron transport in the kidney was modeled by deleting a COX-IV cofactor in the nephron. COX10 is thought to be required for the correct assembly of COX-IV, the terminal enzyme in the respiratory electron transport chain of mitochondria catalyzing the transfer of electrons from cytochrome $c$ to oxygen. $^{36}$ For its catalytic function, COX-IV must dimerize and form a complex with prosthetic groups: heme ( $\alpha$ and $\alpha_{3}$ ), two copper centers $\left(\mathrm{Cu}_{\mathrm{A}}\right.$ and $\left.\mathrm{Cu}_{\mathrm{B}}\right)$, zinc, and magnesium. ${ }^{68}$ 
COX10 is also required in the heme $\alpha$ biosynthesis. ${ }^{35}$ In humans, germline COX10 loss-of-function mutations result in fatal outcomes, and they present with ataxia, muscle weakness, hypotonia, a pyramidal syndrome, and leukodystrophy accompanied with elevated cerebrospinal fluid and blood lactate levels. ${ }^{36,69}$ They may also have anemia, sensorineural deafness and hypertrophic cardiomyopathy, Leigh syndrome ${ }^{70}$ and Leigh-like syndrome. ${ }^{71}$ Patients have been reported to present with a Fanconi syndrome because of a proximal tubulopathy. ${ }^{72}$ These results provide a possible explanation why patients experiencing mitochondrial cytopathies frequently manifest glomerular diseases and indicate that loss-of-function mutations in COX-IV subunits and auxiliary proteins cause FSGS. Moreover, these studies are consistent with a model in which multiple insults to mitochondrial health, by either genetic predisposition or environmental exposures, can trigger FSGS in patients.

A major consequence of loss of COX10 is the loss of ATP production by cells of the nephron that require high energy production to perform the physiological roles of the nephron. It is likely, therefore, that loss of cell function is a major consequence of COX-IV disruption and is in keeping with our reports of the consequences of mitochondrial dysfunction when mitochondrial turnover is disrupted. ${ }^{9}$ Such loss of function leading to cellular degeneration may be sufficient to cause all of the hallmarks of kidney disease demonstrated in these studies. However, as described above, mitochondria also sense and coordinate innate immune responses, and these findings suggest disrupting mitochondrial function may additionally lead to activation of the innate immune response.

Although loss of COX10 and consequent COX-IV dysfunction could be highly deleterious to cell health, previous studies using myofiber- and neuron-specific $\operatorname{Cox} 10^{4 / \Delta}$ mice showed unexpected results. ${ }^{32,73}$ Surprisingly, myofiber-specific $\operatorname{Cox}_{10} 0^{/ / \Delta}$ mice were indistinguishable from controls from birth until early adulthood ( $<3$ months of age), and muscles in adult $\operatorname{Cox} 10^{\Delta / \Delta}$ mice (at 2.5 months of age) contracted at $80 \%$ to $100 \%$ of controls without any sign of oxidative damage or apoptosis. COX-IV activity in muscles of myofiber-specific $\operatorname{Cox} 10^{\Delta / \Delta}$ mice was not completely abolished, maintaining $2 \%$ to $13 \%$ of normal activity, depending on age, which was indicative of bypass mechanisms of COX10 deletion. ${ }^{32}$ Similarly, oxidative stress in the central nervous system of neuron-specific $\operatorname{Cox} 10^{4 / \Delta}$ mice was not evident in mice $<4$ months of age. ${ }^{73}$ These findings imply that glycolysis and residual COX-IV activity can compensate for the deletion of Cox10 in these tissues, whereas such compensatory mechanisms are not sufficient in the nephron. Recent studies in human kidney cells indicate that, in disease states, oxidative phosphorylation is decreased. Glycolysis is highly upregulated in kidney stromal cells, whereas epithelial cells fail to compensate by up-regulating glycolysis. ${ }^{74}$ It remains elusive why glycolysis is not up-regulated in the nephron and needs further investigation beyond the scope of this study. Nevertheless, the kidney epithelium, including podocytes, appears to be particularly susceptible to loss of COX10 and COX-IV.

A series of recent studies by other investigators implicate the release of mtDNA into the cytosol as a link between mitochondrial dysfunction and high interferon activity. ${ }^{20,30,75}$ mtDNA shares certain similarities with prokaryotic DNA and has been reported to interact with cyclic GMP-AMP synthase and thereby activate STING, which, in turn, activates a cascade of signaling intermediates, including TBK1 and IRF3. These reports, however, have focused on immune cells, including macrophages, dendritic cells, and T cells. ${ }^{27,76-81}$ The studies reported to date have also focused on cell death or transfection as methods to release mtDNA into the cytosol, and they also demonstrated an important role of mtDNA signaling inside of immune cells in enabling clearance of pathogens. One study generated a heterozygous mouse model of mitochondrial transcription factor A deficiency, which led to mitochondrial dysfunction in fibroblasts and was sufficient to elicit mtDNA-dependent activation of STING and an interferon response. ${ }^{20}$ In the studies presented herein, a cofactor of COX-IV formation was deleted to elicit mitochondrial dysfunction in the epithelium. This was sufficient to drive mitochondrial dysfunction, intracellular mtDNA release, and activation of STING. In vivo as well as in vitro, this triggered a strong ISG response; however, there were several notable differences between reports of the consequences of mtDNA release in leukocytes and fibroblasts compared with our results in the epithelium. First, although specific activation of STING and TBK1 was detected, activation of IRF3 was not identified in in vitro studies; rather, IRF7 was strongly activated. IRF7 and IRF5 are important independent nuclear factors that result in interferon production. ${ }^{82,83}$ Although further studies are required, it may be that in the epithelium STING mediates its effect predominantly by an IRF3-independent mechanism. Second, it was demonstrated that the epithelium elicits a strong interferon- $\beta$ response rather than a strong interferon- $\alpha$ response. Such a bias toward interferon- $\beta$ has been reported elsewhere and may have implications for the sensitivity of the kidney to the interferon response. ${ }^{84}$

Although this current report provides some evidence for mtDNA release as a cause of kidney inflammation, further work is required to establish whether the mtDNA-STING pathway is important in human disease and whether mitochondrial dysfunction triggered by toxins or other disease states, such as diabetes or Alport syndrome, similarly causes mtDNA release in the setting of mitochondrial dysfunction. Furthermore, the significance of local interferon production in the kidney has been little studied, and the contribution to local injury and inflammation requires further study. ${ }^{85}$ Nevertheless, in the setting of mouse models of kidney injury and glomerular inflammation, deficiency in the major interferon receptor, interferon- $\alpha / \beta$ receptor, has been reported to result in less severe kidney injury ${ }^{86-89}$; deficiency of other sensors of intracytoplasmic nucleic acids, including 
mitochondrial antiviral signaling protein, has also been reported to contribute to disease severity in the kidney. ${ }^{90}$

To study the impact of mitochondrial disruption on the cellular level, TECs were isolated from $\operatorname{Cox} 10^{\Delta / \Delta}$ kidneys, but purified TECs from $\operatorname{Cox} 10^{4 / \Delta}$ kidneys were not viable in cell culture. Thus, an alternative approach was used by silencing Cox 10 mRNA expression in WT TECs. In Cox10silenced cells, a decrease in mitochondrial function in basal conditions and at maximal respiration was detected, indicating a reduction in reserve capacity. MMP was modestly reduced, and no change was detected in viability. This finding was in line with the data from MitoTracker staining of Cox10-ablated fibroblasts. ${ }^{60}$ One possible explanation why there was a reduction in oxygen consumption rate, whereas the MMP was relatively preserved, is that proton pumping by the complexes I, III, and IV (COX-IV) maintains the MMP. The complexes I and III may compensate during COX-IV failure. Indeed, F1F0 ATP synthase (complex V) inhibition has been shown to cause MMP hyperpolarization. ${ }^{91}$ Nevertheless, this observation suggests that mtDNA can leak into the cytosol in the absence of overall mitochondrial depolarization, although it does not exclude the possibility of localized MMP depolarization, as has been identified in other studies. ${ }^{92}$ It is worth noting that the knockdown protocol resulted in approximately $75 \%$ reduction in Cox10 mRNA levels; therefore, the complete effects of COX10 deficiency may not be manifest, whereas purification of epithelium from $\operatorname{Cox} 10^{\Delta / \Delta}$ kidneys resulted in nonviable cell cultures.

The generated mouse model causes loss of function of COX10 in both podocytes and tubular cells of the nephron. Future work to further dissect the specific impact of COX10 mutation on podocytes in vivo using podocyte-restricted expression of Cre recombinase to mutate COX10 would add to our understanding of the kinetics of glomerular pathology progression in the absence of coexistent tubular disease.

In summary, deletion of the mitochondrial COX-IV cofactor heme A:farnesyltransferase in nephron epithelial cells causes severe FSGS, directly implicating mitochondrial dysfunction in the causal pathway of FSGS. Mitochondrial dysfunction resulting from COX-IV deficiency also drives an interferon response that may contribute to kidney pathology and organ failure. This study provides evidence to suggest that the interferon response in the kidney epithelium is caused by intracellular release of mtDNA from the dysfunctioning mitochondria.

\section{Acknowledgments}

We thank Kelly Hudkins (University of Washington), Campbell Kaynor, Chris Roberts, and Norm Allaire (Biogen Inc.) for technical assistance; and Irina Leaf (Biogen Inc.) and Yoonseok Kam (Agilent Technologies) for helpful discussion.

\section{Supplemental Data}

Supplemental material for this article can be found at https://doi.org/10.1016/j.ajpath.2018.08.018.

\section{References}

1. Lowik MM, Groenen PJ, Levtchenko EN, Monnens LA, van den Heuvel LP: Molecular genetic analysis of podocyte genes in focal segmental glomerulosclerosis: a review. Eur J Pediatr 2009, 168: $1291-1304$

2. Dinour D, Mini S, Polak-Charcon S, Lotan D, Holtzman EJ: Progressive nephropathy associated with mitochondrial tRNA gene mutation. Clin Nephrol 2004, 62:149-154

3. Finsterer J: Mitochondriopathies. Eur J Neurol 2004, 11:163-186

4. Niaudet P, Rotig A: The kidney in mitochondrial cytopathies. Kidney Int 1997, 51:1000-1007

5. Genovese G, Friedman DJ, Ross MD, Lecordier L, Uzureau P, Freedman BI, Bowden DW, Langefeld CD, Oleksyk TK, Uscinski Knob AL, Bernhardy AJ, Hicks PJ, Nelson GW, Vanhollebeke B, Winkler CA, Kopp JB, Pays E, Pollak MR: Association of trypanolytic ApoL1 variants with kidney disease in African Americans. Science 2010, 329:841-845

6. Vanwalleghem G, Fontaine F, Lecordier L, Tebabi P, Klewe K, Nolan DP, Yamaryo-Botte Y, Botte C, Kremer A, Burkard GS, Rassow J, Roditi I, Perez-Morga D, Pays E: Coupling of lysosomal and mitochondrial membrane permeabilization in trypanolysis by APOL1. Nat Commun 2015, 6:8078

7. Ma L, Chou JW, Snipes JA, Bharadwaj MS, Craddock AL, Cheng D, Weckerle A, Petrovic S, Hicks PJ, Hemal AK, Hawkins GA, Miller LD, Molina AJ, Langefeld CD, Murea M, Parks JS, Freedman BI: APOL1 renal-risk variants induce mitochondrial dysfunction. J Am Soc Nephrol 2017, 28:1093-1105

8. Brown EJ, Schlondorff JS, Becker DJ, Tsukaguchi H, Tonna SJ, Uscinski AL, Higgs HN, Henderson JM, Pollak MR: Mutations in the formin gene INF2 cause focal segmental glomerulosclerosis. Nat Genet 2010, 42:72-76

9. Kawakami T, Gomez IG, Ren S, Hudkins K, Roach A, Alpers CE, Shankland SJ, D’Agati VD, Duffield JS: Deficient autophagy results in mitochondrial dysfunction and FSGS. J Am Soc Nephrol 2015, 26: 1040-1052

10. Bhargava P, Schnellmann RG: Mitochondrial energetics in the kidney. Nat Rev Nephrol 2017, 13:629-646

11. Che R, Yuan Y, Huang S, Zhang A: Mitochondrial dysfunction in the pathophysiology of renal diseases. Am J Physiol Ren Physiol 2014, 306:F367-F378

12. Kottgen A, Glazer NL, Dehghan A, Hwang SJ, Katz R, Li M, et al: Multiple loci associated with indices of renal function and chronic kidney disease. Nat Genet 2009, 41:712-717

13. Hagiwara M, Yamagata K, Capaldi RA, Koyama A: Mitochondrial dysfunction in focal segmental glomerulosclerosis of puromycin aminonucleoside nephrosis. Kidney Int 2006, 69:1146-1152

14. Lim K, Steele D, Fenves A, Thadhani R, Heher E, Karaa A: Focal segmental glomerulosclerosis associated with mitochondrial disease. Clin Nephrol Case Stud 2017, 5:20-25

15. Park E, Kang HG, Choi YH, Lee KB, Moon KC, Jeong HJ, Nagata M, Cheong HI: Focal segmental glomerulosclerosis and medullary nephrocalcinosis in children with ADCK4 mutations. Pediatr Nephrol 2017, 32:1547-1554

16. Alcubilla-Prats P, Sole M, Botey A, Grau JM, Garrabou G, Poch E: Kidney involvement in MELAS syndrome: description of 2 cases. Med Clin (Barc) 2017, 148:357-361

17. Park E, Ahn YH, Kang HG, Yoo KH, Won NH, Lee KB, Moon KC, Seong MW, Gwon TR, Park SS, Cheong HI: COQ6 mutations in 
children with steroid-resistant focal segmental glomerulosclerosis and sensorineural hearing loss. Am J Kidney Dis 2017, 70:139-144

18. Korkmaz E, Lipska-Zietkiewicz BS, Boyer O, Gribouval O, Fourrage C, Tabatabaei M, Schnaidt S, Gucer S, Kaymaz F, Arici M, Dinckan A, Mir S, Bayazit AK, Emre S, Balat A, Rees L, Shroff R, Bergmann C, Mourani C, Antignac C, Ozaltin F, Schaefer F; PodoNet Consortium: ADCK4-associated glomerulopathy causes adolescence-onset FSGS. J Am Soc Nephrol 2016, 27:63-68

19. Arnoult D, Soares F, Tattoli I, Girardin SE: Mitochondria in innate immunity. EMBO Rep 2011, 12:901-910

20. West AP, Khoury-Hanold W, Staron M, Tal MC, Pineda CM, Lang SM, Bestwick M, Duguay BA, Raimundo N, MacDuff DA, Kaech SM, Smiley JR, Means RE, Iwasaki A, Shadel GS: Mitochondrial DNA stress primes the antiviral innate immune response. Nature 2015, 520:553-557

21. White MJ, McArthur K, Metcalf D, Lane RM, Cambier JC, Herold MJ, van Delft MF, Bedoui S, Lessene G, Ritchie ME, Huang DC, Kile BT: Apoptotic caspases suppress mtDNA-induced STING-mediated type I IFN production. Cell 2014, 159:1549-1562

22. Gutteridge JM: Free radicals in disease processes: a compilation of cause and consequence. Free Radic Res Commun 1993, 19:141-158

23. Ray PD, Huang BW, Tsuji Y: Reactive oxygen species (ROS) homeostasis and redox regulation in cellular signaling. Cell Signal 2012, 24:981-990

24. Holmstrom KM, Finkel T: Cellular mechanisms and physiological consequences of redox-dependent signalling. Nat Rev Mol Cell Biol 2014, 15:411-421

25. Chan YK, Gack MU: Viral evasion of intracellular DNA and RNA sensing. Nat Rev Microbiol 2016, 14:360-373

26. Sun Q, Sun L, Liu HH, Chen X, Seth RB, Forman J, Chen ZJ: The specific and essential role of MAVS in antiviral innate immune responses. Immunity 2006, 24:633-642

27. Sun L, Wu J, Du F, Chen X, Chen ZJ: Cyclic GMP-AMP synthase is a cytosolic DNA sensor that activates the type I interferon pathway. Science 2013, 339:786-791

28. Ablasser A, Hemmerling I, Schmid-Burgk JL, Behrendt R, Roers A, Hornung V: TREX1 deficiency triggers cell-autonomous immunity in a cGAS-dependent manner. J Immunol 2014, 192:5993-5997

29. Cai X, Chiu YH, Chen ZJ: The cGAS-cGAMP-STING pathway of cytosolic DNA sensing and signaling. Mol Cell 2014, 54:289-296

30. West AP: Mitochondrial dysfunction as a trigger of innate immune responses and inflammation. Toxicology 2017, 391:54-63

31. Lood C, Blanco LP, Purmalek MM, Carmona-Rivera C, De Ravin SS, Smith CK, Malech HL, Ledbetter JA, Elkon KB, Kaplan MJ: Neutrophil extracellular traps enriched in oxidized mitochondrial DNA are interferogenic and contribute to lupus-like disease. Nat Med 2016, 22:146-153

32. Diaz F, Thomas CK, Garcia S, Hernandez D, Moraes CT: Mice lacking COX10 in skeletal muscle recapitulate the phenotype of progressive mitochondrial myopathies associated with cytochrome c oxidase deficiency. Hum Mol Genet 2005, 14:2737-2748

33. Humphreys BD, Valerius MT, Kobayashi A, Mugford JW, Soeung S, Duffield JS, McMahon AP, Bonventre JV: Intrinsic epithelial cells repair the kidney after injury. Cell Stem Cell 2008, 2:284-291

34. Kobayashi A, Valerius MT, Mugford JW, Carroll TJ, Self M, Oliver G, McMahon AP: Six2 defines and regulates a multipotent self-renewing nephron progenitor population throughout mammalian kidney development. Cell Stem Cell 2008, 3:169-181

35. Tzagoloff A, Nobrega M, Gorman N, Sinclair P: On the functions of the yeast COX10 and COX11 gene products. Biochem Mol Biol Int 1993, 31:593-598

36. Diaz F: Cytochrome c oxidase deficiency: patients and animal models. Biochim Biophys Acta 2010, 1802:100-110

37. Fukui H, Diaz F, Garcia S, Moraes CT: Cytochrome c oxidase deficiency in neurons decreases both oxidative stress and amyloid formation in a mouse model of Alzheimer's disease. Proc Natl Acad Sci U S A 2007, 104:14163-14168
38. Hatakeyama H, Goto YI: Respiratory chain complex disorganization impairs mitochondrial and cellular integrity: phenotypic variation in cytochrome c oxidase deficiency. Am J Pathol 2017, 187:110-121

39. Committee for the Update of the Guide for the Care and Use of Laboratory AnimalsNational Research Council: Guide for the Care and Use of Laboratory Animals: Eighth Edition. Washington, DC, National Academies Press, 2011

40. Nakagawa N, Barron L, Gomez IG, Johnson BG, Roach AM, Kameoka S, Jack RM, Lupher ML Jr, Gharib SA, Duffield JS: Pentraxin-2 suppresses c-Jun/AP-1 signaling to inhibit progressive fibrotic disease. JCI Insight 2016, 1:e87446

41. Ma LJ, Fogo AB: Model of robust induction of glomerulosclerosis in mice: importance of genetic background. Kidney Int 2003, 64:350-355

42. Li B, Castano AP, Hudson TE, Nowlin BT, Lin SL, Bonventre JV, Swanson KD, Duffield JS: The melanoma-associated transmembrane glycoprotein Gpnmb controls trafficking of cellular debris for degradation and is essential for tissue repair. FASEB J 2010, 24: 4767-4781

43. Baek JH, Birchmeier C, Zenke M, Hieronymus T: The HGF receptor/Met tyrosine kinase is a key regulator of dendritic cell migration in skin immunity. J Immunol 2012, 189:1699-1707

44. Dobin A, Davis CA, Schlesinger F, Drenkow J, Zaleski C, Jha S, Batut P, Chaisson M, Gingeras TR: STAR: ultrafast universal RNAseq aligner. Bioinformatics 2013, 29:15-21

45. Li B, Dewey CN: RSEM: accurate transcript quantification from RNA-Seq data with or without a reference genome. BMC Bioinformatics 2011, 12:323

46. Love MI, Huber W, Anders S: Moderated estimation of fold change and dispersion for RNA-seq data with DESeq2. Genome Biol 2014, 15:550

47. Kramer A, Green J, Pollard J Jr, Tugendreich S: Causal analysis approaches in Ingenuity Pathway Analysis. Bioinformatics 2014, 30: $523-530$

48. Huang DW, Sherman BT, Lempicki RA: Systematic and integrative analysis of large gene lists using DAVID bioinformatics resources. Nature Protoc 2009, 4:44-57

49. Huang DW, Sherman BT, Lempicki RA: Bioinformatics enrichment tools: paths toward the comprehensive functional analysis of large gene lists. Nucleic Acids Res 2009, 37:1-13

50. Bai J, Cervantes C, Liu J, He S, Zhou H, Zhang B, Cai H, Yin D, Hu D, Li Z, Chen H, Gao X, Wang F, O'Connor JC, Xu Y, Liu M, Dong LQ, Liu F: DsbA-L prevents obesity-induced inflammation and insulin resistance by suppressing the mtDNA release-activated cGAScGAMP-STING pathway. Proc Natl Acad Sci U S A 2017, 114: 12196-12201

51. Dib B, Lin H, Maidana DE, Tian B, Miller JB, Bouzika P, Miller JW, Vavvas DG: Mitochondrial DNA has a pro-inflammatory role in AMD. Biochim Biophys Acta 2015, 1853:2897-2906

52. Kriz W, Shirato I, Nagata M, LeHir M, Lemley KV: The podocyte's response to stress: the enigma of foot process effacement. Am J Physiol Ren Physiol 2013, 304:F333-F347

53. Lopez-Novoa JM, Rodriguez-Pena AB, Ortiz A, Martinez-Salgado C, Lopez Hernandez FJ: Etiopathology of chronic tubular, glomerular and renovascular nephropathies: clinical implications. J Transl Med 2011, 9:13

54. Neilson EG: Mechanisms of disease: fibroblasts-a new look at an old problem. Nat Clin Pract Nephrol 2006, 2:101-108

55. Ichimura T, Bonventre JV, Bailly V, Wei H, Hession CA, Cate RL, Sanicola M: Kidney injury molecule-1 (KIM-1), a putative epithelial cell adhesion molecule containing a novel immunoglobulin domain, is up-regulated in renal cells after injury. J Biol Chem 1998, 273: $4135-4142$

56. Humphreys BD, Xu F, Sabbisetti V, Grgic I, Movahedi Naini S, Wang N, Chen G, Xiao S, Patel D, Henderson JM, Ichimura T, Mou S, Soeung S, McMahon AP, Kuchroo VK, Bonventre JV: Chronic epithelial kidney injury molecule-1 expression causes murine kidney fibrosis. J Clin Invest 2013, 123:4023-4035 
57. Baek JH, Zeng R, Weinmann-Menke J, Valerius MT, Wada Y, Ajay AK, Colonna M, Kelley VR: IL-34 mediates acute kidney injury and worsens subsequent chronic kidney disease. J Clin Invest 2015, $125: 3198-3214$

58. Baek JH, Many GM, Evesson FJ, Kelley VR: Dysferlinopathy promotes an intramuscle expansion of macrophages with a cytodestructive phenotype. Am J Pathol 2017, 187:1245-1257

59. Crow MK: Type I interferon in the pathogenesis of lupus. J Immunol 2014, 192:5459-5468

60. Diaz F, Fukui H, Garcia S, Moraes CT: Cytochrome c oxidase is required for the assembly/stability of respiratory complex I in mouse fibroblasts. Mol Cell Biol 2006, 26:4872-4881

61. Galluzzi L, Lopez-Soto A, Kumar S, Kroemer G: Caspases connect celldeath signaling to organismal homeostasis. Immunity 2016, 44:221-231

62. Niemir ZI, Stein H, Dworacki G, Mundel P, Koehl N, Koch B, Autschbach F, Andrassy K, Ritz E, Waldherr R, Otto HF: Podocytes are the major source of IL-1 alpha and IL-1 beta in human glomerulonephritides. Kidney Int 1997, 52:393-403

63. Abdul-Sater AA, Said-Sadier N, Lam VM, Singh B, Pettengill MA, Soares F, Tattoli I, Lipinski S, Girardin SE, Rosenstiel P, Ojcius DM: Enhancement of reactive oxygen species production and chlamydial infection by the mitochondrial Nod-like family member NLRX1. J Biol Chem 2010, 285:41637-41645

64. Tattoli I, Carneiro LA, Jehanno M, Magalhaes JG, Shu Y, Philpott DJ, Arnoult D, Girardin SE: NLRX1 is a mitochondrial NOD-like receptor that amplifies NF-kappaB and JNK pathways by inducing reactive oxygen species production. EMBO Rep 2008, 9: 293-300

65. Stokman G, Kors L, Bakker PJ, Rampanelli E, Claessen N, Teske GJD, Butter L, van Andel H, van den Bergh Weerman MA, Larsen PWB, Dessing MC, Zuurbier CJ, Girardin SE, Florquin S, Leemans JC: NLRX1 dampens oxidative stress and apoptosis in tissue injury via control of mitochondrial activity. J Exp Med 2017, 214: $2405-2420$

66. Bertani T, Abbate M, Zoja C, Corna D, Perico N, Ghezzi P, Remuzzi G: Tumor necrosis factor induces glomerular damage in the rabbit. Am J Pathol 1989, 134:419-430

67. Baud L, Ardaillou R: Tumor necrosis factor in renal injury. Miner Electrolyte Metab 1995, 21:336-341

68. Tsukihara T, Aoyama H, Yamashita E, Tomizaki T, Yamaguchi H, Shinzawa-Itoh K, Nakashima R, Yaono R, Yoshikawa S: The whole structure of the 13-subunit oxidized cytochrome c oxidase at $2.8 \mathrm{~A}$. Science 1996, 272:1136-1144

69. Valnot I, von Kleist-Retzow JC, Barrientos A, Gorbatyuk M, Taanman JW, Mehaye B, Rustin P, Tzagoloff A, Munnich A, Rotig A: A mutation in the human heme A:farnesyltransferase gene (COX10 ) causes cytochrome c oxidase deficiency. Hum Mol Genet 2000, 9:1245-1249

70. Antonicka H, Leary SC, Guercin GH, Agar JN, Horvath R, Kennaway NG, Harding CO, Jaksch M, Shoubridge EA: Mutations in COX10 result in a defect in mitochondrial heme A biosynthesis and account for multiple, early-onset clinical phenotypes associated with isolated COX deficiency. Hum Mol Genet 2003, 12:2693-2702

71. Coenen MJ, van den Heuvel LP, Ugalde C, Ten Brinke M, Nijtmans LG, Trijbels FJ, Beblo S, Maier EM, Muntau AC, Smeitink JA: Cytochrome c oxidase biogenesis in a patient with a mutation in COX10 gene. Ann Neurol 2004, 56:560-564

72. Klootwijk ED, Reichold M, Unwin RJ, Kleta R, Warth R, Bockenhauer D: Renal Fanconi syndrome: taking a proximal look at the nephron. Nephrol Dial Transplant 2015, 30:1456-1460

73. Diaz F, Garcia S, Padgett KR, Moraes CT: A defect in the mitochondrial complex III, but not complex IV, triggers early ROS-dependent damage in defined brain regions. Hum Mol Genet 2012, 21:5066-5077

74. Lemos DR, McMurdo M, Karaca G, Wilflingseder J, Leaf IA, Gupta N, Miyoshi T, Susa K, Johnson BG, Soliman K, Wang G, Morizane R,
Bonventre JV, Duffield JS: Interleukin-1beta activates a MYC-dependent metabolic switch in kidney stromal cells necessary for progressive tubulointerstitial fibrosis. J Am Soc Nephrol 2018, 29:1690-1705

75. Rongvaux A, Jackson R, Harman CC, Li T, West AP, de Zoete MR, Wu Y, Yordy B, Lakhani SA, Kuan CY, Taniguchi T, Shadel GS, Chen ZJ, Iwasaki A, Flavell RA: Apoptotic caspases prevent the induction of type I interferons by mitochondrial DNA. Cell 2014, 159:1563-1577

76. Roberts TL, Idris A, Dunn JA, Kelly GM, Burnton CM, Hodgson S, Hardy LL, Garceau V, Sweet MJ, Ross IL, Hume DA, Stacey KJ: HIN-200 proteins regulate caspase activation in response to foreign cytoplasmic DNA. Science 2009, 323:1057-1060

77. Fernandes-Alnemri T, Yu JW, Datta P, Wu J, Alnemri ES: AIM2 activates the inflammasome and cell death in response to cytoplasmic DNA. Nature 2009, 458:509-513

78. Wu J, Sun L, Chen X, Du F, Shi H, Chen C, Chen ZJ: Cyclic GMPAMP is an endogenous second messenger in innate immune signaling by cytosolic DNA. Science 2013, 339:826-830

79. Li XD, Wu J, Gao D, Wang H, Sun L, Chen ZJ: Pivotal roles of cGAS-cGAMP signaling in antiviral defense and immune adjuvant effects. Science 2013, 341:1390-1394

80. Gao D, Wu J, Wu YT, Du F, Aroh C, Yan N, Sun L, Chen ZJ: Cyclic GMP-AMP synthase is an innate immune sensor of HIV and other retroviruses. Science 2013, 341:903-906

81. Barber GN: STING-dependent cytosolic DNA sensing pathways. Trends Immunol 2014, 35:88-93

82. Honda K, Yanai H, Negishi H, Asagiri M, Sato M, Mizutani T, Shimada N, Ohba Y, Takaoka A, Yoshida N, Taniguchi T: IRF-7 is the master regulator of type-I interferon-dependent immune responses. Nature 2005, 434:772-777

83. Lazear HM, Lancaster A, Wilkins C, Suthar MS, Huang A, Vick SC, Clepper L, Thackray L, Brassil MM, Virgin HW, Nikolich-Zugich J, Moses AV, Gale M Jr, Fruh K, Diamond MS: IRF-3, IRF-5, and IRF7 coordinately regulate the type I IFN response in myeloid dendritic cells downstream of MAVS signaling. PLoS Pathog 2013, 9: e1003118

84. Jaitin DA, Roisman LC, Jaks E, Gavutis M, Piehler J, Van der Heyden J, Uze G, Schreiber G: Inquiring into the differential action of interferons (IFNs): an IFN-alpha2 mutant with enhanced affinity to IFNAR1 is functionally similar to IFN-beta. Mol Cell Biol 2006, 26 : $1888-1897$

85. Anders HJ, Lichtnekert J, Allam R: Interferon-alpha and -beta in kidney inflammation. Kidney Int 2010, 77:848-854

86. Santiago-Raber ML, Baccala R, Haraldsson KM, Choubey D, Stewart TA, Kono DH, Theofilopoulos AN: Type-I interferon receptor deficiency reduces lupus-like disease in NZB mice. J Exp Med 2003, 197:777-788

87. Hron JD, Peng SL: Type I IFN protects against murine lupus. J Immunol 2004, 173:2134-2142

88. Nacionales DC, Kelly-Scumpia KM, Lee PY, Weinstein JS, Lyons R, Sobel E, Satoh M, Reeves WH: Deficiency of the type I interferon receptor protects mice from experimental lupus. Arthritis Rheum 2007, 56:3770-3783

89. Freitas MC, Uchida Y, Lassman C, Danovitch GM, Busuttil RW, Kupiec-Weglinski JW: Type I interferon pathway mediates renal ischemia/reperfusion injury. Transplantation 2011, 92:131-138

90. Subramanian N, Natarajan K, Clatworthy MR, Wang Z, Germain RN: The adaptor MAVS promotes NLRP3 mitochondrial localization and inflammasome activation. Cell 2013, 153:348-361

91. Wang Y, Hou Q, Xiao G, Yang S, Di C, Si J, Zhou R, Ye Y, Zhang Y, Zhang H: Selective ATP hydrolysis inhibition in F1Fo ATP synthase enhances radiosensitivity in non-small-cell lung cancer cells (A549). Oncotarget 2017, 8:53602-53612

92. Ng AC, Baird SD, Screaton RA: Essential role of TID1 in maintaining mitochondrial membrane potential homogeneity and mitochondrial DNA integrity. Mol Cell Biol 2014, 34:1427-1437 